\title{
A Comprehensive Predictive Corrosion Model incorporating varying Environmental Gas Pollutants applied to Wider Steel Applications
}

Dr. Mian Hammad Nazir (corresponding author)

NanoCorr Energy and Modelling Research Group (NCEM)

Bournemouth University Talbot Campus, Poole, Dorset BH12 5BB

Tel: +44 1202967221

Email: hnazir@bournemouth.ac.uk

Dr. Adil Saeed

Global College of Engineering and Technology

P.O.Box 2546, CPO Ruwi 112,

Muscat Sultanate Oman

Tel: +9824227900

Email: asaeed@gcet.edu.om

Professor Zulfiqar A Khan

NanoCorr Energy and Modelling Research Group (NCEM)

Bournemouth University Talbot Campus, Poole, Dorset BH12 5BB

Tel: +44 1202961645

Email: zkhan@bournemouth.ac.uk 


\begin{abstract}
A comprehensive model has been developed to predict uniform corrosion rate of structural steel under the effect of low $\mathrm{pH}$ conditions for example, acid rain. Acid rain is mainly caused by emissions of sulphur dioxide $\left(\mathrm{SO}_{2}\right)$ which reacts with the water droplets in the atmosphere to produce acidic solution which is the primary cause of corrosion of steel structures such as bridges, high value assets, weathering of stone buildings and statues. A fivestage approach was applied to mathematically describe the model as: (i) the growth rate of air-suspended water droplets (i.e. moisture) depending on the condensation/evaporation rate, (ii) the absorption of gas phase $\mathrm{SO}_{2}$ in the droplets forming bisulfite $\mathrm{HSO}_{3}^{-}$ions, (iii) the coalescence of these $\mathrm{SO}_{2}$ absorbed water droplets under the effects of wind speed and gravity, (iv) the deposition rate of $\mathrm{SO}_{2}$ absorbed droplets on steel substrate depending on the inclination and azimuth angles of steel surfaces and, (v) the corrosion rate of steel due to the deposition of these $\mathrm{SO}_{2}$ absorbed droplets. The incorporation of all of the above stages develops a comprehensive corrosion prediction model which includes both the electrochemical parameters and large number of physical, environmental and material parameters. Experiments were performed to analyse the corrosion rate of steel samples by exposing them to moist $\mathrm{SO}_{2}$ corrosion test. A comparative analysis between the modelled predictions and experimental results was performed to verify the reliability of the model. The predictive trends of corrosion rate of steel were also generated for various values of temperature, relative humidity and $\mathrm{SO}_{2} \mathrm{~mole}$ percentage. This research provides design solutions and guidelines against degradation due to aggressive application environments. Enhanced corrosion resistivity within large structures, installations, automotive, locomotives, aerospace and building with historic biography will aid longevity and cost savings.
\end{abstract}

Keywords: Steel; Uniform corrosion; $\mathrm{SO}_{2}$; Mathematical model; Simulation.

\title{
1. Introduction
}

Previous investigation of coating failures, i.e. blistering, delamination, micro-cracks and corrosion damage measurement in real time has been reported [1-15]. Recently a simplistic model of variation in environmental parameters to understand the effects of changing relative humidity and temperatures in terms of corrosion initiation and propagation on bare steel samples has been published [8]. In this paper a predictive model for corrosion of steel considering corrosive species i.e. sulphur, which has implications on the durability of products and systems in the wider steel applications has been developed and presented.

The accumulation of water vapours as electrolyte on surfaces to initiate corrosion has been widely considered, but little or no work has been conducted on dynamics of the accumulation of vapours such as pressure gradients, gravity, speed and orientation of surfaces relative to vapour deposition. This research combines corrosion initiation and propagation incorporating sulphur as an environmental pollutant, its effects on steel and considers micro-dynamic vapour pressure concepts into its modelling techniques.

This paper is part of the wider project to obtain reliable data for long term service and a symmetric approach to minimise structural deterioration because of chemical and mechanical wear [1-14]. Both mechanisms when work alone or in combination poses risk of component failures in normal and/or aggressive environments.

Industrial atmosphere contains $\mathrm{SO}_{2}$ as a major contaminant which poses a great threat in-and-around the larger industrial sites, not only due to its toxic nature but also in terms of structural deterioration as a result of intense corrosion under high acidic (low $\mathrm{pH}$ ) conditions for example acid rain [16]. When acid rain and dry acid particles fall to earth, sulphuric/sulphurous acid that makes the particles acidic can land on culturally important objects such as statues and monuments, buildings, and other manmade structures such as bridges, and damage their surfaces. The acid particles corrode metal and cause paint to deteriorate more quickly. Aircraft industry also faces serious challenges, when it comes to the operating conditions of aircraft. For example, all aircraft are liable to have dissolved solutions of acidic gases from pollution as well as engine exhaust gases [17]. The rate of corrosion in the presence of $\mathrm{SO}_{2}$ increases in the company of moisture. $\mathrm{SO}_{2}$ in the presence of moisture gets converted in to $\mathrm{H}_{2} \mathrm{SO}_{3}$ (eq. 1) which upon reaction with oxyhydroxide formed initially, gives corrosion product $\mathrm{FeSO}_{4}$ (eq. 2). Much of the $\mathrm{SO}_{2}$ is converted to $\mathrm{SO}_{3}$ in the upper atmosphere.

$$
\begin{aligned}
& \mathrm{SO}_{2}+\mathrm{H}_{2} \mathrm{O} \rightarrow \mathrm{H}_{2} \mathrm{SO}_{3} \quad(\text { Sulphurous acid }) \\
& \mathbf{2 F e O O H}+2 \mathrm{H}_{2} \mathrm{SO}_{3} \rightarrow 2 \mathrm{FeSO}_{4}+2 \mathrm{H}_{2} \mathrm{O}+\mathrm{H}_{2}
\end{aligned}
$$

Worldwide $\mathrm{SO}_{2}$ emission data shows that the overall $\mathrm{SO}_{2}$ concentrations in East Asia (China, Mangolia, South Korea and Japan) show increasing trends [18] which in turn results in the increasing trends of acid rain $(\mathrm{pH})$ in 
East Asia (major cause of corrosion failure). Moreover, a recent study showed that, between 2005 and 2014 , $\mathrm{SO}_{2}$ emissions in India has gone up by an enormous 71 percent from what it was in 2005 [19]. Although, $\mathrm{SO}_{2}$ emission in US has decreased by 34 percent (according to department for US Environmental Protection Agency[20]), and in UK by 65 percent in past 10 years (according to department for Environment Food \& Rural Affairs [21]), but still, $\mathrm{SO}_{2}$ emission poses a great threat near industrial areas (for example parts of London and Glasgow, Cardiff, Swansea and Port Talbot) in terms of high corrosive degradation of metal structures[16].

This research develops a comprehensive predictive model for structural steel corrosion in $\mathrm{SO}_{2}$ contaminated atmosphere. However, for simplicity, the present study is mainly focused on investigating the laboratory experimental conditions related with the corrosion problems of structural steel AISI 1010 with $\mathrm{SO}_{2}-\mathrm{O}_{2}-\mathrm{H}_{2} \mathrm{O}$ impurities. The model can be used to simulate the real industrial environments, as the model is equally applicable for predications of wider steel types (such as Ferritic, Austenitic, and Martensitic) under multiple gases pollutants (such as carbon monoxide, nitrogen dioxide and lower atmosphere ozone). This model also helps in corrosion predictions by considering the dynamics of accumulation of $\mathrm{SO}_{2}$ enriched water vapours such as pressure gradients, gravity, wind speed and orientation of steel surfaces relative to vapour deposition. The experiment was performed to analyse the corrosion rate of steel AISI 1010 in moist air containing $\mathrm{SO}_{2}$. The model predictions were compared with the experimental results to verify the reliability of model.

Some models such as $[22,23]$ predict the corrosion of mild steel in thin water film with $\mathrm{SO}_{2}$ diffusion. However, these models only simulate the corrosion mechanism by assuming certain value of thin water film thickness at the start of model. This assumption eventually evades the effects of many vital pre-water deposition parameters (physical, environmental) which may directly affect the thickness of water film deposition on steel surface and eventually could significantly change the corrosive reactions due to $\mathrm{SO}_{2}$ diffusion. Our model fills this gap by considering pre-water deposition parameters and linking them to post-water deposition corrosive reactions.

\section{Experimental}

\subsection{Samples Preparation}

A thin carbon steel (AISI-SAE-1010) substrate with thickness $\mathrm{s}=0.05 \mathrm{~cm}$ was used to prepare three test samples with dimensions $15 \mathrm{~cm}$ x $10 \mathrm{~cm}$ each. The reason for selecting AISI 1010 is its wide applicability for numerous general engineering and structural applications. During the process of samples preparation, no chemicals were used. The chemical composition of the AISI 1010, by \% weight, is: C (0.13\%), Si (0.05), Mn $(0.60 \%), \mathrm{S}(0.050 \%), \mathrm{P}(0.040 \%)$ and balanced Fe $(99.18 \%)$ [24]. The surface conditioning of steel samples was performed by using polishing wheel with emery paper of 200 grit size to achieve an average roughness (Ra) of $0.193 \mu \mathrm{m}$. After polishing, the conditioned samples were cleaned with a $35 \mathrm{~min}$ immersion into a constantly stirred solution of 50g/L Turco 4215 NC-LT. After completing this alkaline cleaning the samples were rinsed with deionized water and air dried. Weight was recorded to the nearest fifth significant figure and the steel samples were stored in a desiccator. To ensure the repeatability, the experimental data was collected from three samples each adhered with corrosion sensor with dimensions $40 \mathrm{~mm}$ x 20mm x $0.1 \mathrm{~mm}$ [25]. All the samples were adhered with the corrosion sensors in order to monitor the corrosion rate in real time (fig. 1 (a)). The sensors were connected to the data acquisition unit (DAQ) (fig. 1 (b)), from where the data was retrieved in PC by using a wired interface (RS232). The software, installed in PC, converts LPR and resistance data into a corrosion rate. The sensors consist of multiple plates made from the material of interest which form the three electrodes. The electrodes are used in conjunction with a potentiostat for conducting LPR measurements. The use of a relatively large counter electrode minimizes polarization effects at the counter electrode to ensure that a stable reference potential is maintained throughout the experiment. Potential step-sweeps are performed by applying a series of 30 steps over a range of $\pm 10 \mathrm{mV}$ spanning a period of $2.6 \mathrm{~s}$ [26]. Corrosion sensors measure the polarization resistance $\mathrm{R}_{\mathrm{p}}(\Omega)$ between the corrosive agents (electrolytic solution) and the steel samples. The polarization resistance is then used to calculate the corrosion current density ' $i$ ' at the interface by using SternGeary equation as [27],

$$
\mathbf{i}=\mathbf{B} / \mathbf{R}_{\mathbf{p}}
$$

Where, B is called Stern-Geary constant. The corrosion current density ' $\mathrm{i}$ ' is measured from the polarization resistance values by using a Stern-Geary constant of $30 \mathrm{mV}$ for carbon steel [24]. The corrosion current density ' $\mathrm{i}$ ' is used to calculate the corrosion rate ( $\mathrm{mm} / \mathrm{year}$ ) by using following eq.

$$
C R=\frac{i K \cdot E_{W}}{\rho A}
$$


Where, $\mathrm{K}$ is the constant that defines the units for the corrosion rate; $\mathrm{E}_{\mathrm{W}}$ is the equivalent weight in grams/equivalent of steel; $\rho$ is the density in $\mathrm{g} / \mathrm{cm}^{3} ; \mathrm{A}$ is the area of sample in $\mathrm{cm}^{2}$.

The sensor was adhered to the conditioned face of the steel sample with industrial strength epoxy. The bonding agent (industrial strength epoxy) was placed on the opposite edges of the sensor so as to adhere the sensor to the conditioned surface of the steel sample in a manner such that the ambient environment is allowed to rapidly diffuse between the sensor and the steel. The sensor array includes at least two interlaced inert electrodes which are manufactured of a noble metal. The noble metal could be $\mathrm{Au}, \mathrm{Pt}$ and $\mathrm{Pd}$ because of the low contact resistances. The noble metals are principally inert such that the sensor array does not readily corrode in typical ambient environments.

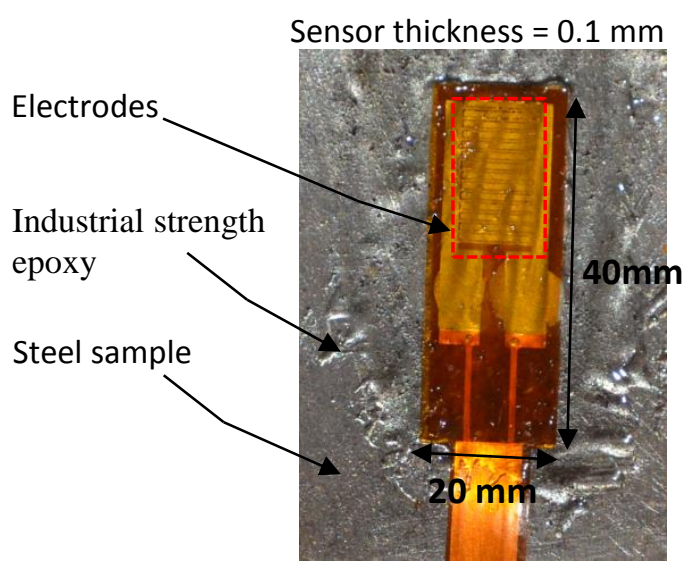

(a)

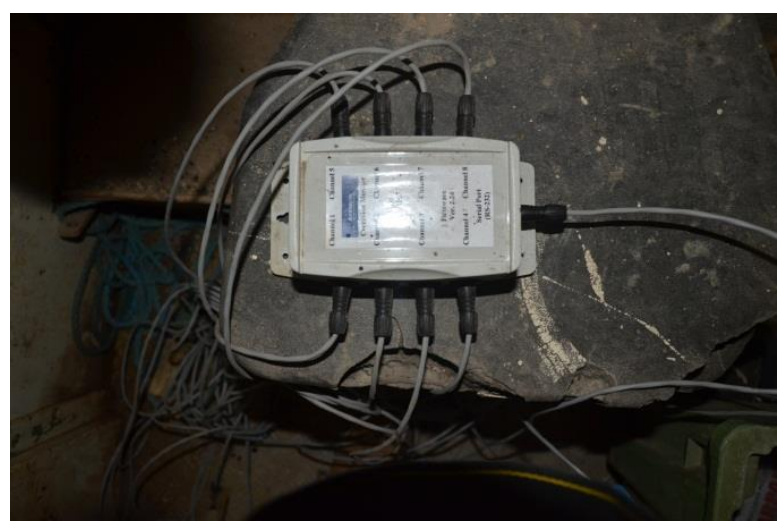

(b)

Figure 1. (a) The corrosion sensor (b) The data acquisition unit (DAQ) which is connected with the sensors and is placed outside the chamber for real time corrosion rate monitoring

\section{Accelerated Corrosion Testing}

To evaluate materials ability to resist corrosion when subjected to moist $\mathrm{SO}_{2}$ environment, all the samples were exposed to an accelerated corrosion test (ASTM - G 87, Kesternich testing) in an environmental chamber as shown in fig. 1 (c). The gas dosing is done manually with a special apparatus in which the paraffin oil is displaced by the $\mathrm{SO}_{2}$ gas or automatically with an electronic mass flow meter as shown in fig. 1 (d). Strategically located sensors, mounted inside the chamber, monitor the climate continuously and convey this information to the Human Machine Interface (HMI), where it is displayed digitally at the control panel. Temperatures are monitored by precision temperature sensors and displayed to a resolution of $0.1^{\circ} \mathrm{C}$. The chamber is also equipped with a special design of corrosion resistant humidity sensor. This measures the relative humidity electronically inside the chamber and displays this at the HMI as \% RH to a resolution of $1 \%$ RH. The water in the chamber must be refreshed after each test cycle. Moist air containing $\mathrm{SO}_{2}$ quickly produces easily visible corrosion on steel surface in the form resembling that occurring in industrial environments. It is therefore a test medium well suited to detect deficiencies in corrosion resistance associated with unsuitable alloy or composition which are frequently used in various engineering structures.

The samples were exposed to G-87 moist $\mathrm{SO}_{2}$ test inside a chamber which had an internal capacity of $300 \mathrm{~L}$, a supply of $\mathrm{SO}_{2}$ with metering device and a chamber heating system. The samples were positioned at a $60^{\circ}$ angle inside the chamber, as to avoid the direct pathway for condensate on to metals surface. Electrical connections for the corrosion sensors were made to a data acquisition unit positioned outside the chamber by passing extension cables through a bulkhead. Average corrosion data from three samples was acquired at 2 hrs interval. The experiment was performed for constant conditions such that the chamber was heated to $313 \mathrm{~K} \pm 3 \mathrm{~K}$ and, 2 \pm 0.2 litre of distilled water was introduced into the base of chamber along with $\mathrm{SO}_{2}$ mole percent $2.5 \%$, introduced in to the chamber through a gas inlet pipe by using dosing setup. The relative humidity inside the chamber was maintained at $100 \%$ in order to ensure high moisture content for $\mathrm{SO}_{2}$ absorption. A total test of 48 hours test was performed. One test cycle was 24 hours of constant exposure. The water in the chamber and $\mathrm{SO}_{2}$ in the air of chamber was replaced before the beginning of each 24 hours cycle with a minimum disturbance of the test samples. 


\subsection{Experimental Observations}

The corrosion sensors adhered to the steel samples determines the corrosion rate based upon temperature, relative humidity and mole percent of $\mathrm{SO}_{2}$. The corrosion rate of samples with passing time is shown in fig. 2 . The plotted corrosion rate is the average of the two exposed samples for the entire period. The data points in fig. 2 show the decline of corrosion rate of steel samples with immersion time. The decline in corrosion rate might be related to the accumulation of corrosion product over the sample surface due to the increasing thickness of corrosion product. When the samples surface is not covered by corrosion products, the reactants easily can reach the samples surface; therefore, the control procedure of the corrosion rate should be the charge-transfer process. As the corrosion process progresses and corrosion products accumulate, the corrosion product scale thickens, hinders reactants reaching reaction surface, and may change the rate control step gradually to the diffusion process, which reduces the corrosion rate. For a certain specie's concentration in the water film, a thicker corrosion product scale would reduce the concentration gradient value between corrosion product scale surface and the base metal, which effectively reduces the flux of reactants and products through the corrosion product scale and leads to a lower corrosion rate if the corrosion rate control step is the diffusion process. At the same time, it was noted that because the chamber was a closed system (meaning there was no continuous $\mathrm{H}_{2} \mathrm{O} / \mathrm{SO}_{2} / \mathrm{O}_{2}$ input in the chamber), $\mathrm{H}_{2} \mathrm{O} / \mathrm{SO}_{2} / \mathrm{O}_{2}$ was consumed gradually along with the corrosion reaction. After mass conservation calculation, it was found that the reduction rate of $\mathrm{H}_{2} \mathrm{O}$ and $\mathrm{SO}_{2}$ were less than $4 \%$ and $1.3 \%$ respectively, and the calculated maximum reduction rate of $\mathrm{O}_{2}$ was about $12.6 \%$.

The experimental findings were utilised to validate the correctness of predictive corrosion model developed in the next section.

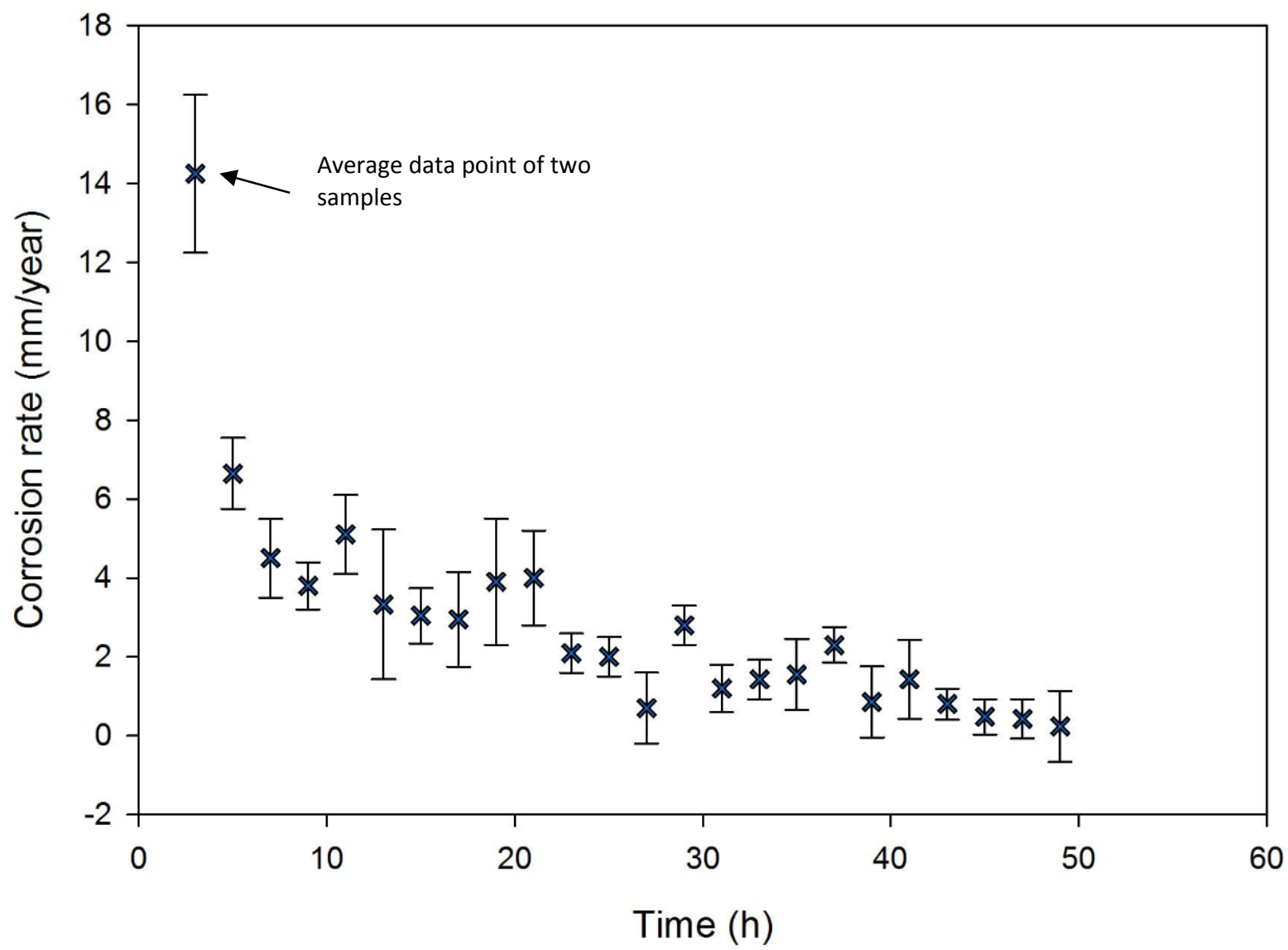

Figure 2. Corrosion rate as a function of time for conditions when temperature was set at $313 \mathrm{~K} \pm 3 \mathrm{~K}, \mathrm{SO}_{2}$ mole percent was kept $2.5 \%$ and relative humidity was maintained at $100 \%$

\section{Mathematical Model}

In this section, a mathematical model is developed to simulate the effects of environmental gas pollutants considering the process of wet deposition. This model is deployable for metal structures, which are stationed in the outdoor environments containing $\mathrm{SO}_{2}$ and other gas pollutants. For simplification in terms of modelling, the model considers the effects of $\mathrm{SO}_{2}$ only, although it is possible to extend to include other gas pollutants. 
The prediction of corrosion rate of steel under the effect of relative humidity and diffusing $\mathrm{SO}_{2}$ mole percent in a non-uniform temperature is carried out in five stages as shown in fig. 3 . In stage 1, the growth equations of an air-suspended water droplet are solved to generate the expressions for the rate at which a droplet grows or decays by condensation or evaporation of water vapour respectively. In stage 2, the transport equations for gasphase $\mathrm{SO}_{2}$ to the droplet are solved which is followed by analysis including both the chemical dissolution and the total flux of $\mathrm{SO}_{2}$ in the liquid phase. In stage 3, the equations for vertical and horizontal coalescence of $\mathrm{SO}_{2}$ absorbed water droplet with neighbouring droplets are developed under the effect of wind speed and gravity. In stage 4 , the deposition equations of water droplets on steel are solved to measure the deposition rate which depends on the inclination and azimuth angles of steel. Finally in stage 5, a mechanistic model has been developed for the prediction of corrosion rate of steel due to deposition of thin water film providing a $\mathrm{SO}_{2}-\mathrm{O}_{2}-$ $\mathrm{H}_{2} \mathrm{O}$ environment for steel corrosion.

Each stage has been modelled separately.

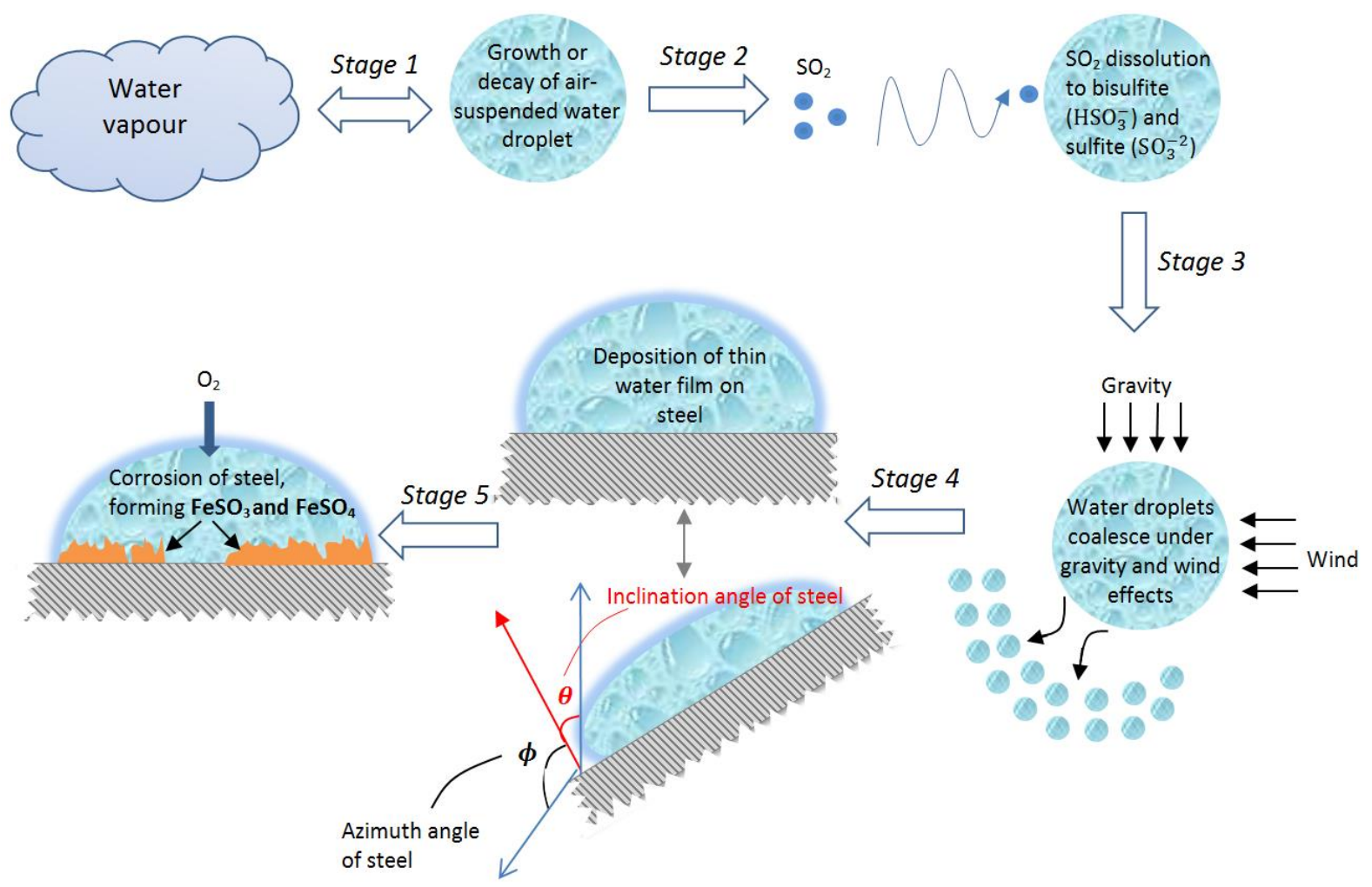

Figure 3. Five-stage model developed in this paper

The interlocking of all five stages develops a holistic framework with large number of physical, environmental, material and chemical parameters which then develop a governing law for predicting the corrosion rate of steel. The corrosion of steel situated in a high relative humidity environment with $\mathrm{SO}_{2}-\mathrm{O}_{2}-\mathrm{H}_{2} \mathrm{O}$ pollutants not only depends on the surface and sub-surface corrosion reactions, but also on the exposure factors of steel i.e. (i) condensation/evaporation rate of air suspended water droplets, (ii) absorption rate of corrosive gas pollutants in these droplets and, (iii) the deposition rate of these droplets on steel depending on wind velocity, gravity as well as the inclination and azimuthal orientations of steel. All these factors have been incorporated to develop an accurate stage-wise sequential corrosion model, which has not been developed in literature.

\subsection{Water droplet formation - Micro-physics of water droplet}

The water droplets in air act as a medium for the transport of corrosive species towards the bare steel therefore causing the steel to corrode. The water droplet in air can nucleate and grow due to condensation process. During this process, the water vapour diffuses from surrounding supersaturated environment towards the droplet surface. Higher condensation rate results in large droplet growth and higher corrosion rate due to increase in the medium for the transport of corrosive species towards steel. Contrarily, if the evaporation rate of droplet become high compared to condensation rate then this eventually results in the decay of existing water droplet in supersaturated environment. This decay causes the reduction of corrosion rate due to descent in the medium for transport of corrosive species towards steel. 
The micro-physics equations of both water droplet condensation and evaporation processes are developed as follows:

\subsubsection{Condensation of air-suspended water droplet}

In supersaturated environment, the droplets can nucleate and grow by condensation process. The process includes diffusion of water vapor to the surface of droplet, thus increasing the size of droplet. This section models the growth mechanism of water droplet in air. The water droplet can act as a medium for the transport of corrosive ions towards bare steel surrounded by supersaturated environment eventually causing the corrosion of steel.

It is well known that the relative humidity $(\mathrm{RH})$ of an air-water mixture is defined as the ratio of the partial pressure of water vapour $\mathbf{p}_{\mathbf{w}}$ in the mixture to the equilibrium saturation vapour partial pressure of water vapour $\mathbf{p}_{\mathbf{s}}$ at a given temperature as,

$$
\begin{array}{r}
\mathrm{RH}=\left(\mathbf{p}_{\mathrm{w}} / \mathbf{p}_{\mathbf{s}}\right) * 100 \\
\mathrm{p}_{\mathrm{s}}=6.1 * 10^{\frac{7.5 * \mathrm{~T}}{237.3+\mathrm{T}}} \\
\mathrm{p}_{\mathrm{w}}=6.1 * 10^{\frac{7.5 * \mathrm{~T}_{\mathrm{d}}}{237.3+\mathrm{T}_{\mathrm{d}}}}
\end{array}
$$

Where, $p_{s}$ rises with increase in temperature $T$ while $p_{w}$ rises with the increase in dew point temperature $T_{d}$. Rise in $p_{w}$ results in increase in concentration of water vapour in air. Water vapour concentration $\left(\mathrm{Kg} / \mathrm{m}^{3}\right)$ found in air is given as,

$$
\mathbf{C}_{\mathrm{H}_{2} \mathrm{O}}=0.00216 *\left(\frac{\mathbf{p}_{\mathrm{w}}}{273.15+\mathrm{T}}\right)
$$

Now, consider a single droplet having radius ' $r$ '. The droplet is located in a supersaturated environment in which the water vapour concentration far-off from the droplet is $\mathrm{C}_{\mathrm{H}_{2} \mathrm{O}}(\infty)$ and the concentration contiguous to the droplet is $\mathrm{C}_{\mathrm{H}_{2} \mathrm{O}}(\mathrm{r})$. It is assumed that the system is in equilibrium which means that air which is surrounding the droplet has negligible accumulation of water vapour. Therefore the per unit time rise in the mass $\mathrm{M}$ of droplet is equivalent to the water vapour flux across the spherical region of radius $\mathrm{x}$ having its centre on the droplet as shown in fig. 4 (a). Hence, the water vapour diffusivity D in air can be related to the growth rate of the droplet as,

$$
\frac{d M}{d t} \int_{x=r}^{x=\infty} \frac{d x}{x^{2}}=4 \pi D \int_{\mathrm{C}_{\mathrm{H}_{2} \mathrm{O}}(r)}^{\mathrm{C}_{\mathrm{H}_{2} \mathrm{O}}(\infty)} d \mathrm{C}_{\mathrm{H}_{2} \mathrm{O}}
$$

Where $\mathrm{C}_{\mathrm{H}_{2} \mathrm{O}}$ represents the water vapour concentration at distance $\mathrm{x}(>\mathrm{r})$ from the droplet. The droplet growth rate $d M / d t$ becomes independent of $\mathrm{x}$ under steady state conditions.

The aforementioned equation is integrated to find a relation between $d M / d t$ and the vapour density difference $\Delta \mathrm{C}_{\mathrm{H}_{2} \mathrm{O}}$ between the droplet surface $(\mathrm{x}=\mathrm{r})$ and the far-off environment $(\mathrm{x}=\infty)$. The equation can be simplified as,

$$
\frac{\mathrm{dM}}{\mathrm{dt}}=4 \pi \mathrm{D}\left[\mathrm{C}_{\mathrm{H}_{2} \mathrm{O}}(\infty)-\mathrm{C}_{\mathrm{H}_{2} \mathrm{O}}(\mathrm{r})\right]
$$

It can be seen that $d M / d t$ is directly proportional to $\Delta \mathrm{C}_{\mathrm{H}_{2} \mathrm{O}}$. The $d M / d t$ is positive if $\Delta \mathrm{C}_{\mathrm{H}_{2} \mathrm{O}}=\mathrm{C}_{\mathrm{H}_{2} \mathrm{O}}(\infty)-$ $\mathrm{C}_{\mathrm{H}_{2} \mathrm{O}}(r)$ is positive, i.e. the flux is towards the droplet if the far-off ambient vapour concentration is greater than the vapour concentration at the droplet surface. This vapour flux adds to the mass of droplet by condensing on its surface.

Substituting $M=\frac{4}{3} \pi r^{3} C_{l}$ into eq. 8 , where $C_{l}$ is the water concentration of droplet,

$$
r \frac{d r}{d t}=D \frac{\Delta C_{H_{2} \mathrm{O}}}{C_{l}}
$$

It is worth noting, that for the case when $\Delta \mathrm{C}_{\mathrm{H}_{2} \mathrm{O}}$ remain constant, the rate of growth of droplet radius $\mathrm{dr} / \mathrm{dt}$ inversely relates to the droplet radius. Consequently, a droplet growing due to condensation, at first, grows quickly in radius but its growth rate reduces with passing time. 


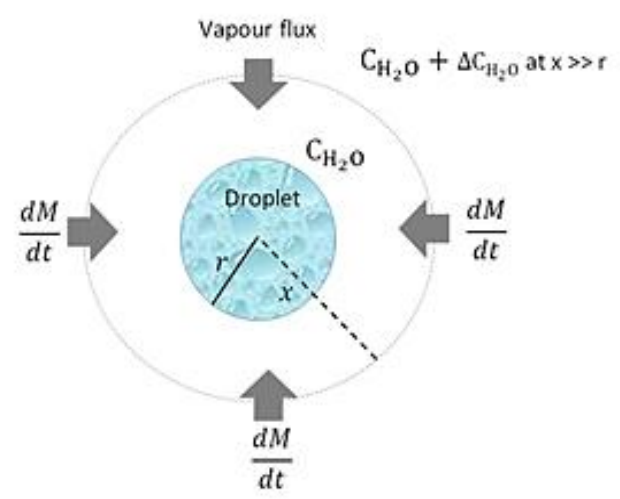

(a)

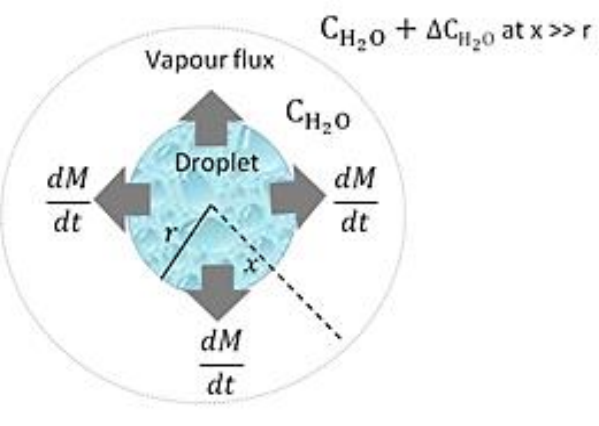

(b)

Figure 4 (a) Vapour diffusing radially inwards towards the surface of a spherical droplet from a higher concentration in surrounding environment (b) Vapour diffusing radially outwards away from the surface of a spherical droplet towards a lower concentration in surrounding environment.

\subsubsection{Evaporation of air-borne water droplet}

Now, consider the case when evaporation rate of spherical droplet is high compared to the condensation rate. The vapor formed at the surface of the droplet is assumed to diffuse into the large body of air that surrounds the droplet.

Consider a droplet with the same specifications as during condensation process. The mass flow of water vapour, from the droplet in to the air, at any distance $\mathrm{x}$ centred on the droplet is shown in fig. 4 (b). For evaporation, $d M / d t$ is negative if $\Delta \mathrm{C}_{\mathrm{H}_{2} \mathrm{O}}=\mathrm{C}_{\mathrm{H}_{2} \mathrm{O}}(\infty)-\mathrm{C}_{\mathrm{H}_{2} \mathrm{O}}(r)$ is negative, i.e. the flux is away from the droplet (evaporating) if the far-off ambient vapour concentration is lower than the vapour concentration at the droplet surface. This vapour flux results in the reduction of droplet mass by evaporating from its surface.

\subsection{Diffusion of corrosive gas in water droplet}

The derivation of partial differential equations which describe corrosive gas transport to an isolated droplet undergoing condensation or evaporation is carried out in three phases.

First, the expressions for the $\mathrm{SO}_{2}$ flux to the droplet are derived by solving gas-phase multicomponent transport equations as shown in fig. 5. Secondly, the analysis for chemical dissolution and electro neutrality are shown and the flux equation of $\mathrm{SO}_{2}$ in the liquid phase is derived. The assumption behind this analysis is that the gasliquid interface is in equilibrium. This indicates that the diffusive resistance is higher in comparison to the interfacial resistance of the gas, which remains valid excluding for very low pressures. Furthermore, the droplet is assumed to be well-mixed all the time and the surface tension effect on vapour pressure is negligible and ignorable. Lastly, all the equations are incorporated with the energy and droplet radius equations. The equations for each phase are discussed as follows:

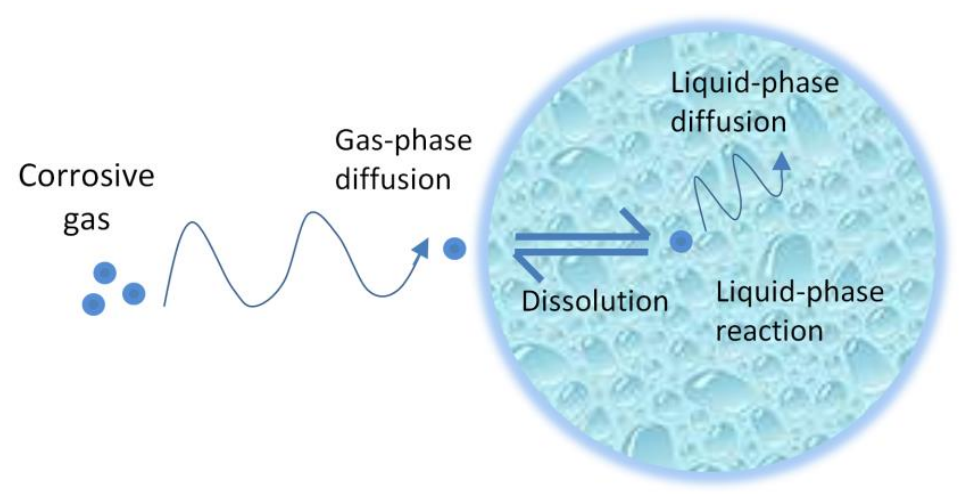


Figure 5. The uptake of gas-phase species by a water droplet. Various processes (gas-phase and liquid-phase) are highlighted.

\subsubsection{Gas-phase equations for diffusion of $\mathrm{SO}_{2}$ in air}

The absorption of corrosive gas by water droplet in the atmosphere can be described by the ordinary diffusion equation of multi-component gases at low density as [28],

$$
\mathbf{N}_{\mathrm{i}}=-\mathbf{C}_{\mathrm{f}} \mathbf{D}_{\mathrm{im}} \frac{d \mathbf{y}_{\mathrm{i}}}{\mathrm{d} \xi}+\mathbf{y}_{\mathrm{i}} \sum_{\mathrm{i}=1}^{\mathrm{g}+1} \mathbf{N}_{\mathrm{j}}
$$

Where, $\mathrm{N}_{\mathrm{i}}$ represents the flux of component $\mathrm{i} ; \mathrm{D}_{\mathrm{im}}$ is the diffusion coefficient of component $\mathrm{i}$; $\mathrm{y}_{\mathrm{i}}$ represents the mole fraction of component $\mathrm{i} ; \mathrm{C}_{\mathrm{f}}$ is the gas concentration which is surrounding the water droplet.

The above equation relates to a droplet which is located in a gas composed of $\mathrm{g}$ components. The component $\mathrm{g}+1$ is the inert gas and $\xi$ is the distance from the droplet centre.

Consider the following boundary conditions,

$$
\mathbf{y}_{\mathbf{i}}=\mathbf{y}_{\mathbf{i}}^{*} \text { and } \mathbf{T}=\mathbf{T}^{*} \text { at } \boldsymbol{\xi}=\mathbf{r}
$$

and

$$
\mathbf{y}_{\mathbf{i}}=\mathbf{y}_{\mathbf{i}}^{\mathbf{B}} \text { and } \mathbf{T}=\mathbf{T}^{\mathbf{B}} \text { at } \boldsymbol{\xi}=\infty
$$

Where the symbols '*' and ' $\mathrm{B}$ ' represent the interfacial and bulk quantities of corrosive gas respectively; $\mathrm{T}$ denotes the temperature.

Now, if the water droplet is moving in atmosphere, then eq. 10 can be modified to include the effect of droplet's motion on flux as [29].

$$
N_{i}=\frac{-N_{N n}^{i} C_{f} D_{i m}}{2} \frac{d y_{i}}{d \xi}+\frac{N_{N n}^{i} y_{i}}{2} \sum_{i=1}^{g+1} N_{j}
$$

Where $\mathrm{N}_{\mathrm{Nn}}$ is the Nusselt number.

Now, if the system is assumed to be in pseudosteady-state, then the rate at which the component $\mathrm{i}$ is transferred through a constant sphere $\xi$ will be constant. Therefore, the flux $\mathrm{J}_{\mathrm{i}}$ at $\xi=\mathrm{r}$ can be related as,

$$
\mathbf{N}_{\mathbf{i}}(\xi)=\frac{\mathbf{r}^{2} \mathbf{J}_{\mathbf{i}}}{\xi^{2}}
$$

Substituting eq. 14 in to eq. 13 gives,

$$
J_{i}=\frac{-N_{N n}^{i}}{2} \frac{C_{f} D_{i m}}{r^{2}} \xi^{2} \frac{d y_{i}}{d \xi}+\frac{N_{N n}^{i}}{2} y_{i} \sum_{i=1}^{g+1} N_{i}
$$

Substituting,

$$
\xi=1 / \eta
$$

and

$$
\frac{d y_{i}}{d \xi}=\frac{d y_{i}}{d \eta} \frac{d \eta}{d \xi}
$$

into eq. 15 and then integrating to the boundary conditions given in eq. 11 and 12 gives,

$$
J_{i}=\frac{N_{N n}^{i}}{2} \frac{\bar{J}\left(y_{i}^{B} \exp \left(-\frac{\bar{I}_{r}}{C_{f} D_{i m}}\right)-y_{i}^{*}\right)}{\exp \left(-\frac{\bar{I}_{r}}{C_{f} D_{i m}}\right)-1}
$$

Where,

$$
\overline{\mathbf{J}}=\sum_{\mathbf{k}=\mathbf{1}}^{\mathrm{g}+\mathbf{1}} \mathbf{J}_{\mathbf{k}}
$$

Eq. 18 describes the general relation for multi-component diffusion of g+1 gases. Assuming $\mathrm{SO}_{2}$ is the only trace gas getting absorbed in the droplet then the expression for the $\mathrm{SO}_{2}$ flux from the gas-phase to the interface can be written by modifying eq. 18 as, 


$$
\mathbf{J}_{\mathbf{S O}_{2}}=\frac{\mathrm{N}_{\mathrm{Nn}}^{\mathrm{i}}}{2} \frac{\overline{\mathrm{J}}\left(\mathrm{PSO}_{2}^{\mathrm{B}} \exp \left(-\frac{\overline{\mathrm{I}}_{\mathrm{r}}}{\mathrm{C}_{\mathrm{f}} \mathrm{D}_{\mathrm{SO}_{2}}}\right)-\mathrm{P}_{\mathrm{SO}_{2}}^{*}\right)}{\exp \left(-\frac{\overline{\mathrm{I}}_{\mathrm{r}}}{\mathrm{C}_{\mathrm{f}} \mathrm{D}_{\mathrm{SO}_{2}}}\right)-1}
$$

\subsubsection{Liquid-phase equations for aqueous absorption and chemical dissolution of $\mathrm{SO}_{2}$}

The above expression describes the gas-phase mass transfer of $\mathrm{SO}_{2}$. However, $\mathrm{SO}_{2}$ exists as physically dissolved when considered in solution and takes the form as $\mathrm{SO}_{2} \cdot \mathrm{H}_{2} \mathrm{O}$, and in dissociated form as bisulfite $\left(\mathrm{HSO}_{3}^{-}\right)$and sulfite $\left(\mathrm{SO}_{3}^{-2}\right)$. The analysis in this section will be restricted to a $\mathrm{SO}_{2} . \mathrm{H}_{2} \mathrm{O}$ and $\mathrm{HSO}_{3}^{-}$system, although it is possible to extend to include $\mathrm{SO}_{3}^{-2}$ and other forms.

The following chemical reactions are considered for $\mathrm{SO}_{2}$ absorption in the solution:

Dissolution of $\mathrm{SO}_{2}$ in the solution:

$$
\mathrm{SO}_{2}(\mathrm{~g})+\mathrm{H}_{2} \mathrm{O} \rightleftharpoons \mathrm{SO}_{2} \cdot \mathrm{H}_{2} \mathrm{O}
$$

$\mathrm{SO}_{2}$ hydrate ionisation equilibrium:

$$
\begin{aligned}
& \mathrm{SO}_{2} \cdot \mathrm{H}_{2} \mathrm{O} \rightleftharpoons \mathrm{H}^{+}+\mathrm{HSO}_{3}^{-} \\
& \mathrm{HSO}_{3}^{-} \rightleftharpoons \mathrm{H}^{+}+\mathrm{SO}_{3}^{2-}
\end{aligned}
$$

Flux of $\mathrm{SO}_{2}, \mathrm{H}_{2} \mathrm{O}$ and $\mathrm{HSO}_{3}^{-}$in solution can be expresses as,

$$
\mathbf{N}_{\mathrm{SO}_{2} \cdot \mathrm{H}_{2} \mathrm{O}}^{*}-\frac{\left[\mathrm{SO}_{2} \cdot \mathrm{H}_{2} \mathrm{O}\right]^{*}}{\mathrm{CT}} \mathbf{x}\left(\mathrm{N}_{\mathrm{SO}_{2} \cdot \mathrm{H}_{2} \mathrm{O}}^{*}+\mathbf{N}_{\mathrm{HSO}_{3}^{-}}^{*}+\mathbf{N}_{\mathrm{H}_{2} \mathrm{O}}^{*}\right)=-\left.\frac{\mathrm{d}}{\mathrm{dx}}\left(\mathrm{D}_{\mathrm{SO}_{2}}^{\mathrm{L}}\left[\mathrm{SO}_{2} \cdot \mathrm{H}_{2} \mathrm{O}\right]^{*}\right)\right|_{\mathbf{x}=\mathbf{0}}
$$

and

$$
\mathbf{N}_{\mathrm{HSO}_{3}}^{*}-\frac{\left[\mathrm{HSO}_{3}\right]^{*}}{\mathrm{CT}} \mathbf{x}\left(\mathbf{N}_{\mathrm{SO}_{2} \cdot \mathrm{H}_{2} \mathrm{O}}^{*}+\mathbf{N}_{\mathrm{HSO}_{3}^{-}}^{*}+\mathbf{N}_{\mathrm{H}_{2} \mathrm{O}}^{*}\right)=-\left.\frac{\mathrm{d}}{\mathrm{dx}}\left(\mathbf{D}_{\mathrm{HSO}_{3}}^{\mathrm{L}}\left[\mathrm{HSO}_{3}\right]^{*}\right)\right|_{\mathbf{x}=\mathbf{0}}
$$

Eq. 24 and 25 can be incorporated to obtain total flux,

$$
\mathbf{N}_{\phi}^{*}-\frac{\phi^{*}}{C T}\left(\mathbf{N}_{\phi}^{*}+\mathbf{N}_{\mathbf{H}_{2} \mathrm{O}}^{*}\right)=-\left.\frac{d}{d x}\left(D_{\mathbf{S O}_{2}}^{L}\left[\mathbf{S O}_{2} \cdot \mathbf{H}_{2} \mathbf{O}\right]^{*}+D_{\mathrm{HSO}_{3}}^{\mathrm{L}}\left[\mathrm{HSO}_{3}\right]^{*}\right)\right|_{\mathbf{x}=\mathbf{0}}
$$

Where,

$$
\mathbf{N}_{\mathbf{\phi}}^{*}=\mathbf{N}_{\mathbf{S O}_{2} \cdot \mathbf{H}_{2} \mathbf{O}}^{*}+\mathbf{N}_{\mathrm{HSO}_{3}}^{*}
$$

The following boundary conditions can be applied if film theory assumptions are utilised,

$$
\text { at } \mathrm{x}=0, \phi=\phi^{*}
$$

and

$$
\text { at } \mathrm{x}=\delta, \quad \phi=\phi^{\mathrm{B}}
$$

Where

$$
\phi=\left[\mathrm{SO}_{2} \cdot \mathrm{H}_{2} \mathrm{O}\right]+\left[\mathrm{HSO}_{3}^{-}\right]
$$

the integration of eq. 26 gives,

$$
\mathbf{N}_{\phi}^{*}=\frac{\phi^{*}}{C T} \mathbf{N}_{\mathbf{H}_{2} \mathrm{O}}^{*}+\mathbf{k}_{\mathrm{L}}^{\mathbf{O}}\left(\phi^{*}-\phi^{\mathrm{B}}\right)-\mathbf{k}_{\mathrm{L}}^{\mathbf{0}} \mathrm{A}\left(\left[\mathrm{HSO}_{3}^{-}\right]^{*}-\left[\mathrm{HSO}_{3}\right]^{\mathrm{B}}\right)
$$

Where $\mathrm{k}_{\mathrm{L}}^{\mathrm{O}}$ is the mass transfer coefficient of $\mathrm{SO}_{2}$ gas in the liquid phase and given as,

$$
\mathbf{k}_{\mathbf{L}}^{\mathbf{O}}=\frac{\mathbf{D}_{\mathbf{S O}_{2}}^{\mathrm{L}_{2}}}{\delta}
$$

and

$$
\mathbf{A}=\mathbf{1}-\frac{\mathbf{D}_{\mathrm{HSO}_{3}-}^{\mathrm{L}}}{\mathbf{D}_{\mathrm{SO}_{2}}^{\mathrm{L}}}
$$

The equilibrium relationship at the interface is given by,

$$
\mathbf{N}_{\mathbf{\phi}}^{*}=-\mathbf{J}_{\mathbf{S O}_{2}}^{\mathbf{g}}
$$


It is worth noting that eq. 34 combines the mass transfer processes for the liquid-phase (eq. 26) with the gasphase (eq. 15). The equation describes that the flux of $\mathrm{SO}_{2}$ in the gas phase should be identical to the flux of absorbed $\mathrm{SO}_{2}$ and dissociated forms in the liquid phase. The coupling expression describing the composition equilibrium on the liquid side and the gas-side of interfacial $\mathrm{SO}_{2}$ is given as

$$
\mathrm{H}\left[\mathrm{SO}_{2} \cdot \mathrm{H}_{2} \mathbf{O}\right]^{*}=\left[\mathrm{SO}_{2}(\mathbf{g})\right]^{*}
$$

Where $\mathrm{H}$ is the constant of Henry's law

\subsubsection{Final dynamic equation for $\mathrm{SO}_{2}$ diffusion in water droplet}

Till now, the equations describe the steady-state mass transport process of $\mathrm{SO}_{2}$. The above equations can be used to establish a system which can be solved for $\mathrm{J}_{\mathrm{SO}_{2}}^{\mathrm{g}}$, $\left[\mathrm{HSO}_{3}^{-}\right],\left[\mathrm{SO}_{2} \cdot \mathrm{H}_{2} \mathrm{O}\right]$ etc considering a water droplet of fixed radius and specified initial conditions. This information can be used to develop a relation for the rate of change in the bulk concentration of absorbed $\mathrm{SO}_{2}$ along the water droplet of radius $\mathrm{r}$ as,

$$
\frac{d \phi^{B}}{d t}=-\frac{3}{r} \mathbf{J}_{\mathrm{SO}_{2}}^{\mathrm{g}}
$$

Eq. 36 describes the mass transfer of $\mathrm{SO}_{2}$ combined with the droplet radius $\mathrm{r}$ (i.e. coupled to eq. 20).

\subsection{Water droplet coalescence and deposition on steel}

Next, the water droplet which has absorbed $\mathrm{SO}_{2}$ from air will coalesce and deposit on the surface of solid structure. In this study, the solid is bare steel which is surrounded by these air suspended droplets. It is assumed that all droplets have the same concentration of absorbed $\mathrm{SO}_{2}$. The deposition rate will depend on droplet vertical and horizontal coalescence, inertial impaction, wind speed and gravitational settling.

Consider a collector droplet having terminal speed $v_{1}$. The radius of droplet is $r_{1}$. Assume that this droplet is moving in space which has identical sized homogeneously distributed droplets of radius $r_{2}$ which are moving with speed $v_{2}$. It is assumed that these droplets are uniformly collected with the same collection rate by the collector droplet. This collection mechanism is demonstrated in fig. 6 . The growth rate of the collector droplet as a result of coalesce is given by [30],

$$
\frac{d M}{d t}=\pi r_{1}^{2}\left(v_{1}-v_{2}\right) w_{1} E_{c}
$$

Where

$$
v_{1}=\sqrt{u_{1}^{2}+g^{2} t^{2}-2 u_{1} g t \sin \theta_{v_{1}}} \text { and } v_{2}=\sqrt{u_{2}^{2}+g^{2} t^{2}-2 u_{2} g t \sin \theta_{v_{2}}}
$$

Where the coalescence efficiency $E_{c}$ of a droplet of radius $r_{2}$ with a collector droplet is defined as the fraction of collisions that result in a coalescence [30]. Substituting $M=\frac{4}{3} \pi r^{3} C_{l}$ in eq. 37 gives

$$
\frac{\mathrm{dr}_{1}}{\mathrm{dt}}=\frac{\left(\mathrm{v}_{1}-\mathrm{v}_{2}\right) \mathrm{w}_{1} \mathrm{E}_{\mathrm{c}}}{4 \mathrm{C}_{\mathrm{l}}}
$$

If $v_{1}>v_{2}$, then the coalescence efficiency is assumed to be equal to unity, so that $E_{c}=E$. Eq. 39 becomes

$$
\frac{\mathrm{dr}_{1}}{\mathrm{dt}}=\frac{\mathrm{v}_{1} \mathrm{w}_{1} E}{4 \mathrm{C}_{1}}
$$

As $v_{1}$ and $E$ both increase with growing $r_{1}$, it can be seen from eq. 40 that $d r_{1} / d t$ also increases with growing $r_{1}$, i.e., the droplet growth by coalescence is a catalytic process. 


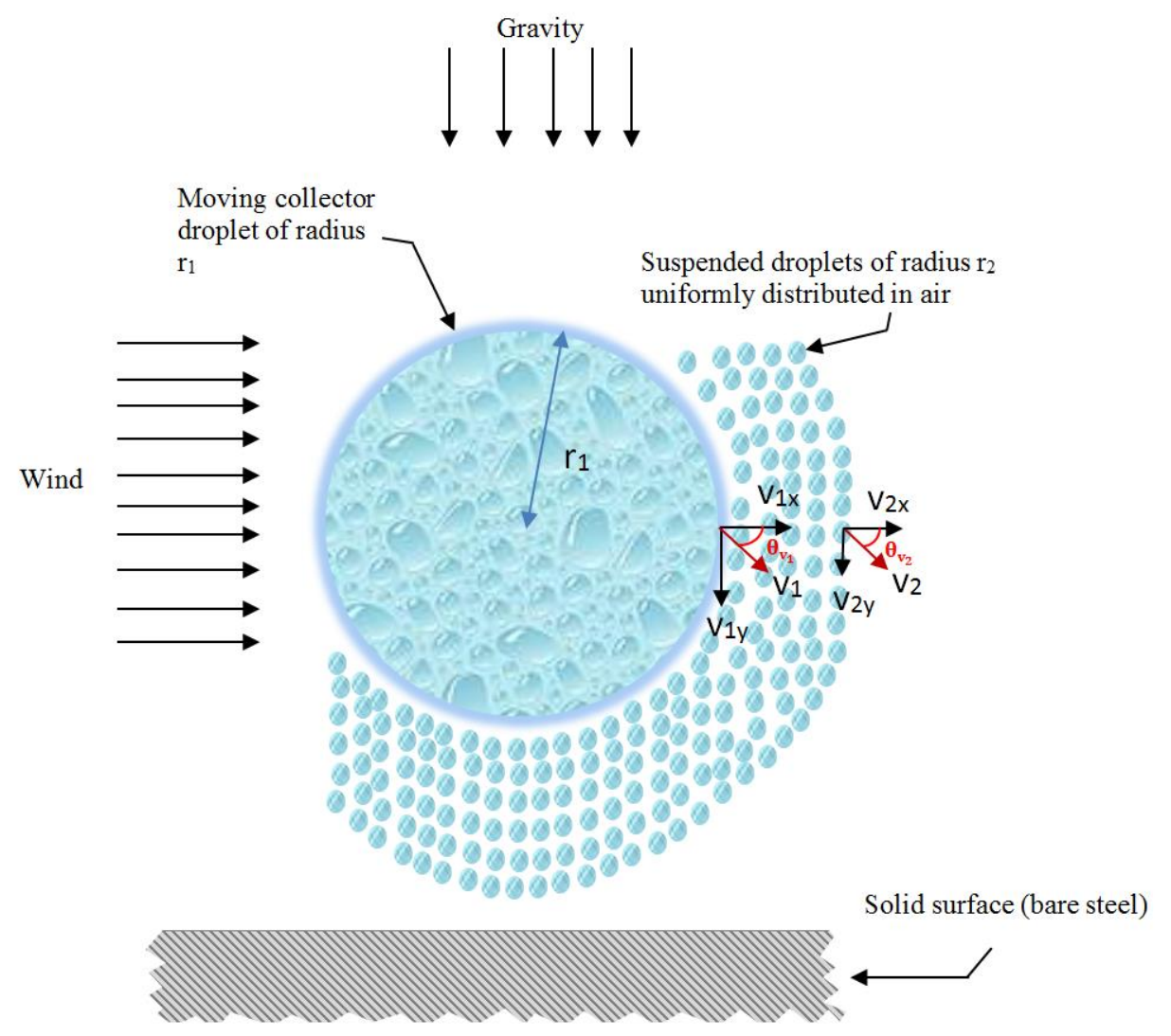

Figure 6. Schematic illustrating the constant growth of a collector droplet due to coalescence

In eq. $40, \mathrm{w}_{\mathrm{l}}$ is the liquid water content, LWC (liquid water content) of the droplets of radius $\mathrm{r}_{2}$. The rate of change in LWC can be given by using advection-diffusion equation as [31],

$$
\frac{d w_{1}}{d t}=-U \cdot \nabla w_{l}+\nabla\left(k_{H} \cdot \nabla w_{l}\right)-S_{I M}-S_{S}
$$

Where $\mathrm{K}_{\mathrm{H}}$ denotes the eddy diffusivity of heat; $\mathrm{S}_{\mathrm{IM}}$ and $\mathrm{S}_{\mathrm{S}}$ respectively are the water deposition terms by inertial impaction and gravitational settling of droplets on bare steel [32]. Inertial impaction is normally the main deposition mechanism, but gravitational settling can play important role under low wind speed conditions; $\mathrm{U}$ is the horizontal wind component. Therefore,

$$
\begin{aligned}
& S_{I M}=A_{L} k_{x} \varepsilon_{I M}|U| w_{l} \\
& S_{S}=A_{L} k_{Z} v_{1} W_{l} \\
& \frac{d U}{d t}=\frac{d}{d z}\left(K_{M} \frac{d U}{d z}\right)
\end{aligned}
$$

Where, $A_{L}$ represents the one-sided area density of bare steel; $\varepsilon_{I M}$ is the inertial impaction efficiency; $K_{M}$ is the eddy diffusivity of momentum; $\mathrm{k}_{\mathrm{x}}$ and $\mathrm{k}_{\mathrm{Z}}$ are respectively the portions of the effective steel area for deposition of droplets (coverage area) by inertial impaction and gravitational settling. These can be written as [33],

$$
\begin{aligned}
& \mathbf{k}_{\mathrm{x}}=\int_{\theta_{\mathrm{L}}=0}^{2 / \pi} \int_{\theta_{\mathrm{L}}=0}^{2 \pi} \phi_{\theta_{\mathrm{L}}} \phi_{\phi_{\mathrm{L}}} \sin \theta_{\mathrm{L}}\left|\cos \phi_{\mathrm{L}}\right| d \theta_{\mathrm{L}} d \phi_{\mathrm{L}} \\
& \mathbf{k}_{\mathrm{z}}=\int_{\theta_{\mathrm{L}}=0}^{2 / \pi} \phi_{\theta_{\mathrm{L}}} \cos \theta_{\mathrm{L}} \mathrm{d} \theta_{\mathrm{L}}
\end{aligned}
$$

Where $\theta_{\mathrm{L}}$ and $\phi_{\mathrm{L}}$ are respectively the inclination and azimuth of steel as shown in fig. 7; $\phi_{\theta_{\mathrm{L}}}$ and $\phi_{\phi_{\mathrm{L}}}$ are the steel angular densities associated with each angle. The angular densities are given as,

$$
\boldsymbol{\phi}_{\theta_{\mathrm{L}}}\left(\alpha_{\mathrm{L}}\right)=\frac{2 \Gamma\left(\mu_{\mathrm{L}}\right)}{\pi \Gamma\left(\mu_{\mathrm{L}}\right)}\left(1-\frac{2 \alpha_{\mathrm{L}}}{\pi}\right)^{\mu_{\mathrm{L}}-1}\left(\frac{2 \alpha_{\mathrm{L}}}{\pi}\right)^{\mathrm{v}_{\mathrm{L}}-1} \quad, \alpha_{\mathrm{L}} \in\left[0 ; \frac{2}{\pi}\right]
$$




$$
\boldsymbol{\phi}_{\phi_{\mathrm{L}}}\left(\alpha_{\mathrm{L}}\right)=\frac{1}{2 \pi} \quad, \alpha_{\mathrm{L}} \in[0 ; 2 \pi]
$$

$\Gamma$ is the Euler Gamma-function, $\mu_{L}$ is a parameter depending on the location of steel. For simplification, it was assumed that all steel orientations are equi-probable, i.e., $\mu_{L}$ is set to be 1 .

The inclination and azimuth angles of steel show the amount of steel surface area occupied by the water film. The effects of deposition rate by inclination and azimuth orientations play a vital role in large complex structures, in which, the surface/or walls have complex geometry and do not exist as complete vertical or horizontal planes. In this model, the coverage and thickness of water film are decided by the user.

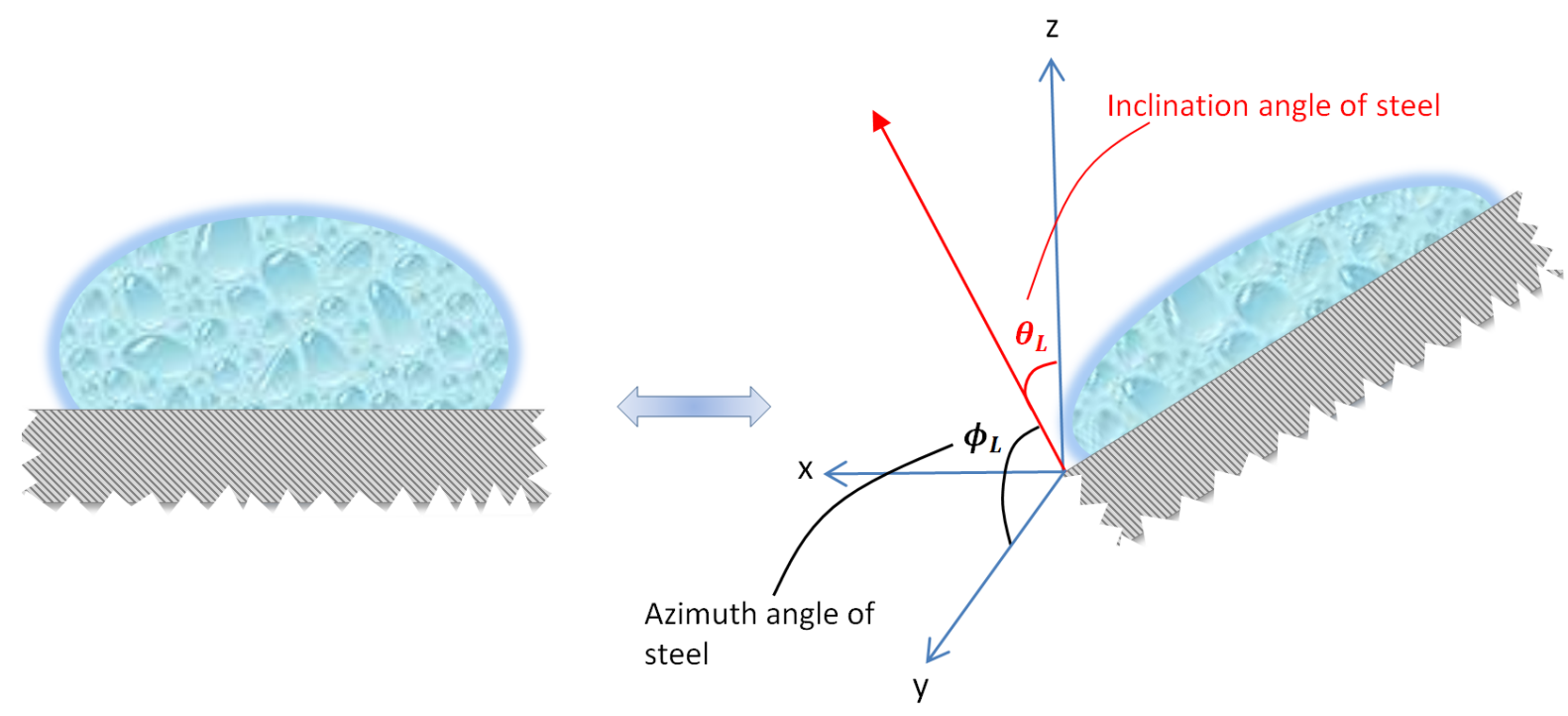

Figure 7. The inclination and azimuth angle of steel which decides the orientation of steel having water droplet deposited on its surface.

\subsection{Corrosion of steel due to $\mathrm{SO}_{2}$ absorbed water droplets deposited on its surface}

The deposition of water droplets on steel surface results in the formation of thin water film. The coverage area of water film is positively associated with the inclination and azimuth angles of steel in addition to relative humidity, as discussed already. This section focuses on the development of a mechanistic model to analyse and predict the uniform corrosion of steel in $\mathrm{SO}_{2}-\mathrm{O}_{2}-\mathrm{H}_{2} \mathrm{O}$ environment.

\subsubsection{Variables and assumptions}

The influences of four variables on corrosion rate are investigated: temperature (293-366K), $\mathrm{SO}_{2}$ mole percent $(0.2-2.5 \%), \mathrm{O}_{2}$ mole percent $(0-2.5 \%)$ and time. The complete corrosion process was distributed into four regions as shown in fig. 8 .

Consider the following three assumptions to simplify the problems:

1. The inclination and azimuth of steel are such that the surface is perfectly horizontal with no inclination and possible azimuth orientation.

2. The mass transfer is assumed to be independent of the effect of electro-migration because the influence of electro-migration to the overall flux of species is negligible.

3. The non-continuous thin water film exists due to droplets on the surface of steel under non-saturated conditions. 


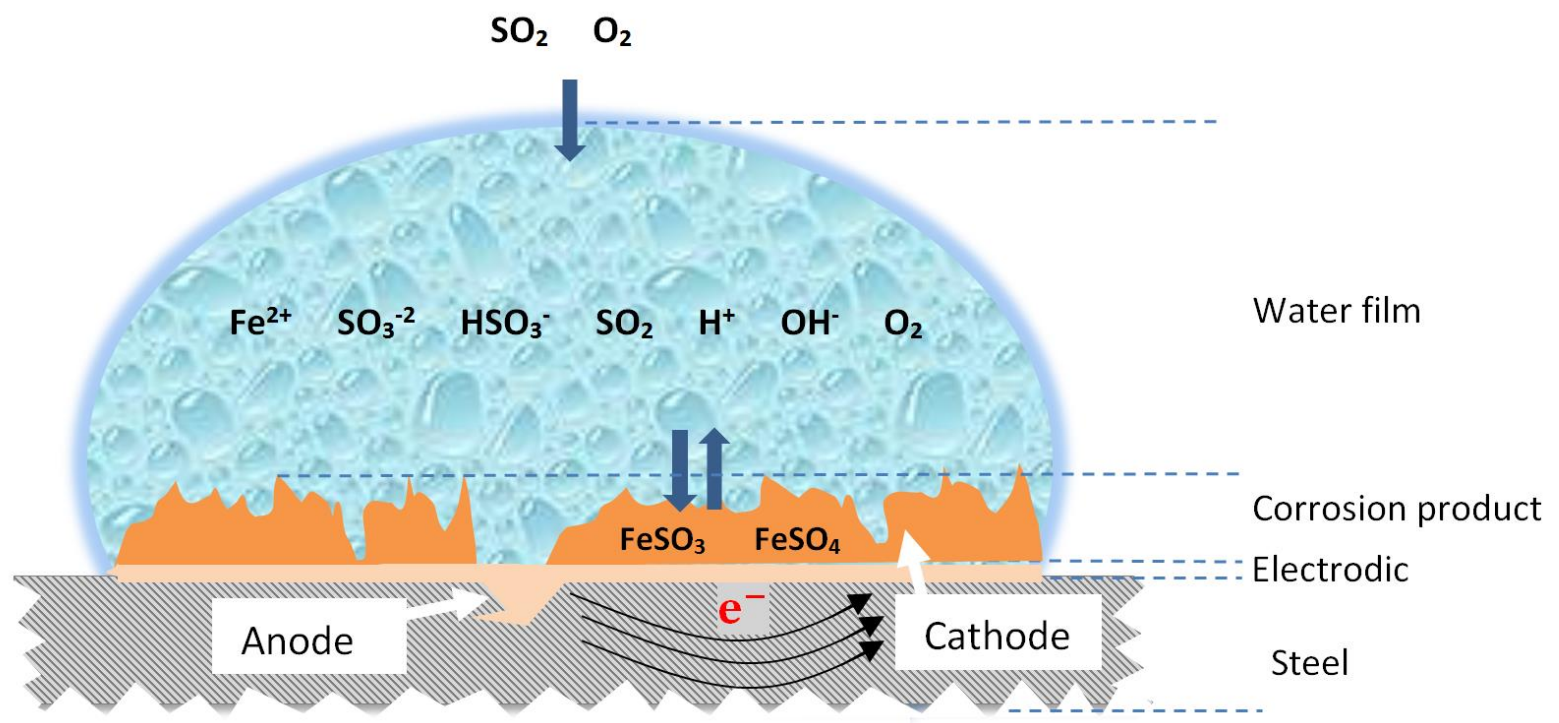

Figure 8. Schematic of the four regions constituting the model (water, corrosion product, electrode region and steel)

\subsubsection{Chemical reactions}

A thin water film is assumed to exist on steel surface during the corrosion process. According to the sequential modelling, the dissolution of $\mathrm{SO}_{2}$ and hydrate ionisation in a water droplet has already taken place before the deposition of water droplet on steel surface, as discussed in previous section (see eq. 21, 22 and 23). However, post deposition of droplet, the oxidation of sulfite and formation of $\mathrm{FeSO}_{3}$ and $\mathrm{FeSO}_{4}$ takes place as,

Oxidation of sulfite:

$$
2 \mathrm{HSO}_{3}^{-}+\mathrm{O}_{2} \rightarrow 2 \mathrm{H}^{+}+2 \mathrm{SO}_{4}^{2-}
$$

Formation of $\mathrm{FeSO}_{3}$ and $\mathrm{FeSO}_{4}$ :

$$
\begin{aligned}
& \mathrm{Fe}^{2+}+\mathrm{SO}_{4}^{2-} \rightarrow \mathrm{FeSO}_{4} \\
& \mathrm{Fe}^{2+}+\mathrm{SO}_{3}^{2-} \rightarrow \mathrm{FeSO}_{3}
\end{aligned}
$$

Based on eq. 21, 22, 23, 46, 47 and 48, the model accounts for eight solution components, namely, $\mathrm{SO}_{2} \cdot \mathrm{H}_{2} \mathrm{O}$, $\mathrm{HSO}_{3}^{-}, \mathrm{SO}_{3}^{2-}, \mathrm{H}^{+}, \mathrm{O}_{2}, \mathrm{Fe}^{2+}, \mathrm{SO}_{4}^{2-}$ and $\mathrm{OH}^{-}$. The model ignores other negligible trace components during calculations.

\subsubsection{Electrochemical reactions}

Anodic reaction:

$$
\mathrm{Fe} \rightarrow \mathrm{Fe}^{2+}+2 \mathbf{e}^{-}
$$

Cathodic reactions:

$$
\begin{aligned}
& 2 \mathrm{H}^{+}+2 \mathrm{e}^{-} \rightarrow \mathrm{H}_{2} \\
& \mathrm{O}_{2}+\mathrm{SO}_{2}+2 \mathrm{e}^{-} \rightarrow \mathrm{SO}_{4}^{2-}
\end{aligned}
$$

The experiment confirmed that the hydrogen evolution reaction existed in this system. The experiment also confirmed that the oxygen depolarization due to cathodic reaction accelerated the corrosion reaction. The $\mathrm{SO}_{2}$ containing environment can result in the cathodic reaction on steel during corrosion process as shown in eq.51, which has also been considered in this model.

\subsubsection{Corrosion model}

The physical zone of corrosion model was distributed into four regions as shown in fig. 8. (water film, corrosion product, electrodic and steel regions). The equations derivations of the chemical and electrochemical processes for these regions are discussed below. The steel region was not included in this model. 


\subsubsection{Water film region equations}

The diffusion of all the components $\left(\mathrm{SO}_{2} \cdot \mathrm{H}_{2} \mathrm{O}, \mathrm{HSO}_{3}{ }^{-}, \mathrm{SO}_{3}{ }^{2-}, \mathrm{H}^{+}, \mathrm{O}_{2}, \mathrm{Fe}^{2+}, \mathrm{SO}_{4}{ }^{2-}\right.$, and $\left.\mathrm{OH}^{-}\right)$in water and corrosion product film is considered. The equation for the mass transfer of these components is expressed by incorporating eq. 36 for the mass transfer of the bulk concentration of absorbed $\mathrm{SO}_{2}$ with time along the water film,

$$
\frac{\mathbf{d} \zeta \phi \mathbf{j}}{\mathbf{d t}}=-\frac{\mathbf{d}}{\mathbf{d x}}\left(\zeta^{1.5} \mathbf{D}_{\mathbf{j}} \frac{\zeta \Phi_{\mathbf{j}}}{\zeta \mathrm{x}}\right)+\zeta \mathbf{R}_{\mathbf{j}}-\left(\mathbf{C R}-\frac{\delta \mathbf{d}_{\mathbf{f}}}{\delta \mathrm{t}}\right) \frac{\zeta \phi_{\mathbf{j}}}{\zeta \mathrm{x}}
$$

Where, $\mathrm{j}$ in $\phi_{\mathrm{j}}$ represents the components and $\phi$ represents the mole concentration for component $\mathrm{j}$; CR represents the corrosion rate $(\mathrm{mm} / \mathrm{year}) ; \zeta$ is the permeability of porous corrosion product; $\mathrm{d}_{\mathrm{f}}$ is the corrosion product thickness $(\mathrm{m}) ; \mathrm{R}_{\mathrm{j}}$ is the chemical reaction rate. The first term on the right hand side represents the diffusion term without the consideration of electro-migration influence. The second term represents the chemical reaction source. The last term considers the convection effect which solves the moving boundary problem due to the formation of corrosion product.

The turbulent diffusion in the water film $\mathrm{D}_{\mathrm{E}}$ depends on the thickness of the pseudo-laminar boundary layer $\mathrm{p}$ and the corrosion product thickness $d_{f}$ as [34],

$$
D_{E}=0.18 v\left[x-\frac{d_{f}}{p}\right]
$$

The turbulent diffusion in corrosion product is ignored.

The total diffusivity $D_{j}$ (shown in eq. 52) now becomes the sum of turbulent diffusion and molecular diffusion $\mathrm{D}_{\mathrm{M}}$ as [35],

$$
\mathbf{D}_{\mathbf{j}}=\mathbf{D}_{\mathbf{E}}+\mathbf{D}_{\mathbf{M}}
$$

The thin water film ultimately becomes a concentrated solution, wherein the water film species deviate from their ideal characteristics.

The ionic strength I significantly influences the activities of components as well as the corrosion rate. Where I is given as [36],

$$
\mathbf{I}=\frac{1}{2} \sum \mathbf{m}_{\mathbf{j}}|\mathbf{z}(\mathbf{j})|^{2}
$$

Where, $\mathrm{m}_{\mathrm{j}}$ is the molality of component $\mathrm{j}$; $\mathrm{z}$ is the component charge number.

The ionic strength I further affects the activity coefficient $\gamma$ for $\mathrm{SO}_{2}$ and $\mathrm{O}_{2}$ which are given as respectively [36],

For $\mathrm{SO}_{2,}$ [37],

$$
\ln \gamma\left(\mathrm{SO}_{2}\right)=\left(\frac{0.0997-22.3}{\mathrm{~T}}\right) \mathrm{I}
$$

Where, $\mathrm{T}$ is the temperature.

For $\mathrm{O}_{2}$, [37],

$$
\ln \gamma\left(\mathbf{O}_{2}\right)=2 \mathbf{m}(S) \lambda_{\mathbf{O}_{2}, S}+\mathbf{m}(S)_{\mathrm{C}} \mathbf{m}(S)_{\mathrm{a}} \varrho_{o_{2}, S}
$$

Where, the other two parameters can be calculated as [38],

$$
\begin{aligned}
& \lambda_{\mathrm{O}_{2}, \mathrm{~S}}=\frac{0.4341-255.5911}{\mathrm{~T}}+\frac{45132.321}{\mathrm{~T}^{2}} \\
& \varrho_{\mathrm{o}_{2}, \mathrm{~S}}=-0.0187
\end{aligned}
$$

Normally the daily-use steel (e.g. AISI 1010) contains a significant amount of Mn, which can be corroded into $\mathrm{Mn}^{2+}$ ion. This ion has a catalytic oxidation effect on sulfite [39]. The catalytic oxidation rate of sulfite is generally expressed as [40],

$$
\mathbf{R}=\mathbf{k c}_{\mathrm{SO}_{3}^{2-}}^{\mathbf{m}} \mathbf{c}_{\mathbf{O}_{2}}^{\mathbf{n}} \mathbf{c}_{\mathrm{Mn}^{2+}}^{\mathbf{q}}
$$




\subsubsection{Corrosion product region equations}

The corrosion products are mainly composed of $\mathrm{FeSO}_{3}$ and $\mathrm{FeSO}_{4}$ crystalline hydrates. $\mathrm{FeSO}_{3}$ does not dissolve in pure water rather it easily dissolves in the presence of $\mathrm{SO}_{2}$. Despite the fact that sulfite oxidation produced sulfate but $\mathrm{FeSO}_{3}$ was also produced at the initial stages of the corrosion reaction [41].

The reason that $\mathrm{FeSO}_{4}$ product film is not produced at the initial stage of corrosion reaction was its high solubility in water. However, the advancement in corrosion reaction resulted in the significant production of $\mathrm{FeSO}_{4}$ at later stages. Further, as the water film reached the super saturation state, $\mathrm{FeSO}_{4}$ started to deposit in the form of solid product film.

The formation rate of product film can be calculated as follows [42],

$$
\mathbf{R}_{\mathrm{G}}=\mathbf{k}_{\mathrm{G}} \Delta \mathbf{c}^{\mathbf{n}_{\mathrm{s}}}
$$

Parameter $\mathrm{n}_{\mathrm{s}}$ defines the crystals size and morphology (with value between 1 and 2), normally taken as 1.6 [42]; $\Delta \mathrm{c}$ is the variable term denoting the change in mass concentration for $\mathrm{FeSO}_{3}$ or $\mathrm{FeSO}_{4}$. This variable can be calculated as,

$$
\begin{aligned}
\Delta \mathrm{c}_{1} & =\mathrm{c}_{\mathrm{m} 1}-\mathrm{S}_{\mathrm{FeSO}_{3}} \\
\Delta \mathrm{c}_{2} & =\mathrm{c}_{\mathrm{m} 2}-\mathrm{S}_{\mathrm{FeSO}_{3}}
\end{aligned}
$$

The concentration difference and super saturation are related as [42],

$$
\Delta \mathbf{c}=\mathbf{S}\left(\mathbf{S}_{\mathbf{S}}-\mathbf{1}\right)
$$

The same type of ion from multiple solvents can provide difficulty in direct measurement of the mass concentration difference $\Delta \mathrm{c}$. Thus, super saturation $\mathrm{S}_{\mathrm{S}}$ is incorporated in eq. 61 to develop the following precipitation rate formula,

$$
\mathbf{R}_{\mathrm{G}}=\mathbf{k}_{\mathrm{G}}\left[\mathbf{S}\left[\mathbf{S}_{\mathbf{S}}-\mathbf{1}\right)\right]^{\mathbf{n}}
$$

$\mathrm{S}_{\mathrm{S}}$ can be calculated for both $\mathrm{FeSO}_{3}$ and $\mathrm{FeSO}_{4}$ by using,

$$
\begin{aligned}
\mathrm{S}_{\mathrm{S} 1} & =\frac{\left[\mathrm{Fe}^{2+}\right] \cdot\left[\mathrm{SO}_{3}^{2-}\right]}{\mathrm{K}_{\mathrm{SP} 1}} \\
\mathrm{~S}_{\mathrm{S} 2} & =\frac{\left[\mathrm{Fe}^{2+}\right] \cdot\left[\mathrm{SO}_{4}^{2-}\right]}{\mathrm{K}_{\mathrm{SP} 2}}
\end{aligned}
$$

$\mathrm{K}_{\mathrm{sp}}$ relates with the mole solubility $\mathrm{S}_{\mathrm{n}}$ as [43]

$$
\mathbf{K}_{\mathrm{SP}}=\mathbf{S}_{\mathbf{n}}^{2}
$$

As per the solubility data of $\mathrm{FeSO}_{3}$ and $\mathrm{FeSO}_{4}$ in water [42], the variation of solubility product with temperature can be used to determine the solubility product. The precipitation rates of $\mathrm{FeSO}_{3}$ and $\mathrm{FeSO}_{4}$ are denoted as precipitation rates, $\mathrm{R}_{\mathrm{G} 1}$ and $\mathrm{R}_{\mathrm{G} 2}$, respectively. The precipitation amount of $\mathrm{FeSO}_{3}$ and $\mathrm{FeSO}_{4}$ can be respectively given as,

$$
\begin{aligned}
& \gamma_{\mathrm{FeSO}_{3}}=\int_{0}^{t} \frac{\mathbf{R}_{\mathrm{G}_{1}} \mathbf{A}}{\mathrm{MFeO}_{3} \cdot 3 \mathrm{H}_{2} \mathrm{O}} \mathbf{d t} \\
& \gamma_{\mathrm{FeSO}_{4}}=\int_{0}^{t} \frac{\mathbf{R}_{\mathrm{G}_{2}} \mathrm{~A}}{\mathrm{M}_{\mathrm{FeSO}_{4}} \cdot 4 \mathrm{H}_{2} \mathrm{O}} \mathbf{d t}
\end{aligned}
$$

Where $\mathrm{M}_{\mathrm{FeSO}_{3}} \mathrm{M}_{\mathrm{FeSO}_{4}}$ are the molar masses of $\mathrm{FeSO}_{3}$ and $\mathrm{FeSO}_{4}$ respectively, the corrosion product thickness of $\mathrm{FeSO}_{3}$ and $\mathrm{FeSO}_{4}$ can be respectively give as,

$$
\begin{aligned}
& \mathbf{d}_{\mathrm{f} 1}=\frac{\mathbf{M}_{\mathrm{FeSO}_{3}} \gamma_{\mathrm{FeSO}_{3}(\mathrm{~s})}}{\boldsymbol{\rho}_{\mathrm{FeSO}_{3}} \mathbf{A}(\mathbf{1 - \varsigma )}} \\
& \mathbf{d}_{\mathrm{f} 2}=\frac{\mathbf{M}_{\mathrm{FeSO}_{4}} \gamma_{\mathrm{FeSO}_{\mathbf{4}}(\mathrm{s})}}{\boldsymbol{\rho}_{\mathrm{FeSO}_{4}} \mathbf{A}(\mathbf{1}-\varsigma)}
\end{aligned}
$$

The average volumetric porosity $\zeta$ is determined by the user. The total corrosion product film thickness is

$$
d_{f}=d_{f \mathbf{1}}+d_{f \mathbf{2}}
$$

For the case when the amount of product film exceeds the sample surface, then the corrosion product may leave the sample surface under the influence of gravity. This specific amount can only be calculated analytically in this model. 


\subsubsection{Electrodic region equations}

This section develops the equations for hydrogen electrode current density $i_{\mathrm{H}+}$ and the anode current density $i_{\mathrm{Fe}}^{2+}[44,45]$.

This model assumes that the diffusion process directly control the oxygen reaction at electrodes, because of the reason that in addition to low diffusion coefficient, oxygen is also less soluble in water. The limit diffusion current density of the oxygen reaction at electrode is,

$$
\mathrm{i}_{\mathrm{lim}, \mathrm{O}_{2}}^{\mathrm{d}}=2 \mathrm{FN}_{\mathrm{O}_{2}}
$$

Where $\mathrm{N}_{\mathrm{O}_{2}}$ is the diffusion flux of $\mathrm{O}_{2}$ and $\mathrm{F}$ is the Faradays constant. The oxygen electrode reaction should be accompanied by $\mathrm{SO}_{2}$. Thus, it is equally important to compare the $\mathrm{SO}_{2}$ flux with the $\mathrm{O}_{2}$ flux to the electrode surface. For the case, when the $\mathrm{SO}_{2}$ flux is lower than the $\mathrm{O}_{2}$ flux, then $\mathrm{i}_{\mathrm{lim}, \mathrm{O}_{2}}^{\mathrm{d}}$ becomes,

$$
\mathrm{i}_{\lim , \mathbf{0}_{2}}^{\mathrm{d}}=2 \mathrm{FN}_{\mathrm{SO}_{2}}
$$

Where $\mathrm{N}_{\mathrm{SO}_{2}}$ is the flux of $\mathrm{SO}_{2}$. The current conservation equation states that,

$$
\mathbf{i}_{\mathbf{F e}}=\mathbf{i}_{\mathbf{H}^{+}}+\mathbf{i}_{\mathbf{O}_{2}}
$$

The relationship between the corrosion rate, CR and the anode current density is as follows [46],

$$
\mathbf{C R}=\frac{\mathrm{K}_{\mathbf{c}}\left(\mathbf{i}_{\mathrm{Fe}} \mathrm{EW}\right)}{\rho}
$$

Where, $\mathrm{K}_{\mathrm{c}}$ is the corrosion rate coefficient; the corrosion potential $\mathrm{E}$ and the anodic current density $\rho$ can be calculated according to procedure in [46].

\section{Modelling Results and Discussion}

The simultaneous solution of equations 9, 34, 36, 37 and 73, which comprise the basic model, yields the corrosion rate of steel under the effect of relative humidity and diffusing $\mathrm{SO}_{2}$ mole percent in a non-uniform temperature. This model is being used to analyse the corrosion rate of steel due to deposition of air-suspended water droplets on steel surface which have absorbed significant amount of $\mathrm{SO}_{2}$ from air during their movement under the effect of wind speed and gravity. The discussion of the results is presented in figs. 10-13 for the variations of time, relative humidity, temperature and $\mathrm{SO}_{2}$ concentration. These results are for a droplet with an initial radius of $20 \mu \mathrm{m}$ and $\mathrm{pH}$ of 2 respectively moving with $2 \mathrm{~m} / \mathrm{s}$ velocity under a horizontal wind/air speed of $1 \mathrm{~m} / \mathrm{s}$ (as inside the climate chamber) through a uniform field of $2.5 \% \mathrm{SO}_{2}$ by weight in an adiabatic atmosphere with a relative humidity of $100 \%$, and a ground level temperature of $296.15 \mathrm{~K}$. The droplet deposit forming a thin water film on horizontal faced carbon steel with no inclination and possible azimuth orientation, such that right after deposition, $\mathrm{O}_{2}$ also starts to diffuse through water film, thus creating a $\mathrm{SO}_{2}-\mathrm{O}_{2}-\mathrm{H}_{2} \mathrm{O}$

\begin{tabular}{|c|c|c|c|c|}
\hline Symbol & Value & Unit & Definition & Reference \\
\hline \multicolumn{5}{|c|}{ Constants } \\
\hline $\mathrm{F}$ & 96485.4 & $\mathrm{C} / \mathrm{mol}$ & Faraday constant & [47] \\
\hline $\mathrm{R}_{\mathrm{g}}$ & 8.3145 & $\mathrm{~J} / \mathrm{mol} \mathrm{K}$ & Molar gas constant & {$[48]$} \\
\hline G & 9.81 & $\mathrm{~m} / \mathrm{sec}^{2}$ & Force of gravitation & [47] \\
\hline $\mathrm{H}$ & 1.4 & $\mathrm{~mol} / \mathrm{kg}$ bar & Henry law constant for $\mathrm{SO}_{2}$ & [48] \\
\hline \multicolumn{5}{|l|}{ Physical } \\
\hline$E_{c}$ & 0.4 & & Coalescence Efficiency & [49] \\
\hline
\end{tabular}
environment which accelerates the corrosion rate of steel. The model parameter and constant inputs are shown in Table 1.

Table 1. Model parameter and constant inputs 


\begin{tabular}{|c|c|c|c|c|}
\hline $\mathrm{i}_{0, \mathrm{H}^{+}}^{r e f}$ & 0.05 & $\mathrm{~A} / \mathrm{m}^{2}$ & $\begin{array}{l}\text { Reference exchange current density for hydrogen } \\
\text { electrode }\end{array}$ & {$[44]$} \\
\hline $\mathrm{i}_{0, \mathrm{Fe}}^{r e f}$ & 1 & $\mathrm{~A} / \mathrm{m}^{2}$ & Anode reference exchange current density & [45] \\
\hline $\mathrm{E}_{\mathrm{Fe}, \mathrm{rev}}$ & -0.488 & $\mathrm{~V}$ & Anode equilibrium potential & [44] \\
\hline \multicolumn{5}{|c|}{ Corrosion product film } \\
\hline$\rho_{\mathrm{FeSO}_{3}}$ & 2096 & $\mathrm{Kg} / \mathrm{m}^{3}$ & Density of $\mathrm{FeSO}_{3} \cdot 3 \mathrm{H}_{2} \mathrm{O}$ & [36] \\
\hline$\rho_{\mathrm{FeSO}_{4}}$ & 2290 & $\mathrm{Kg} / \mathrm{m}^{3}$ & Density of $\mathrm{FeSO}_{4} \cdot 4 \mathrm{H}_{2} \mathrm{O}$ & {$[50]$} \\
\hline \multicolumn{5}{|c|}{ Precipitation } \\
\hline $\mathrm{k}_{\mathrm{G}}$ & 0.218 & & Effective crystal growth rate constant & [42] \\
\hline \multicolumn{5}{|c|}{ Diffusion Coefficients } \\
\hline $\mathrm{D}_{\mathrm{m}, \mathrm{H}^{+}}$ & $9.31 \times 10^{-9}$ & $\mathrm{~m}^{2} / \mathrm{sec}$ & $\mathrm{H}^{+}$diffusion coefficient & [47] \\
\hline $\mathrm{D}_{\mathrm{m}, \mathrm{HSO}_{3}^{-}}$ & $1.54 \times 10^{-9}$ & $\mathrm{~m}^{2} / \mathrm{sec}$ & $\mathrm{HSO}_{3}^{-}$diffusion coefficient & {$[47]$} \\
\hline $\mathrm{D}_{\mathrm{m}, \mathrm{SO}_{3}^{2-}}$ & $0.95 \times 10^{-9}$ & $\mathrm{~m}^{2} / \mathrm{sec}$ & $\mathrm{SO}_{3}^{2-}$ diffusion coefficient & {$[47]$} \\
\hline $\mathrm{D}_{\mathrm{m}, \mathrm{SO}_{2}}$ & $1.86 \times 10^{-9}$ & $\mathrm{~m}^{2} / \mathrm{sec}$ & $\mathrm{SO}_{2}$ diffusion coefficient & {$[51]$} \\
\hline $\mathrm{D}_{\mathrm{m}, \mathrm{O}_{2}}$ & $1.96 \times 10^{-9}$ & $\mathrm{~m}^{2} / \mathrm{sec}$ & $\mathrm{O}_{2}$ diffusion coefficient & [52] \\
\hline $\mathrm{D}_{\mathrm{m}, \mathrm{Fe}^{2+}}$ & $0.71 \times 10^{-9}$ & $\mathrm{~m}^{2} / \mathrm{sec}$ & $\mathrm{Fe}^{2+}$ diffusion coefficient & [47] \\
\hline
\end{tabular}

The predicted corrosion rates and measured corrosion rates from experiments were compared to validate the model reliability as shown in fig. 9. The predicted results of steel corrosion in $\mathrm{SO}_{2}-\mathrm{O}_{2}-\mathrm{H}_{2} \mathrm{O}$ environment are in agreement with the experimental results. In the simulation the model slightly over predicts the corrosion rates for some data points, which makes some points in this graph deviate from the diagonal line.

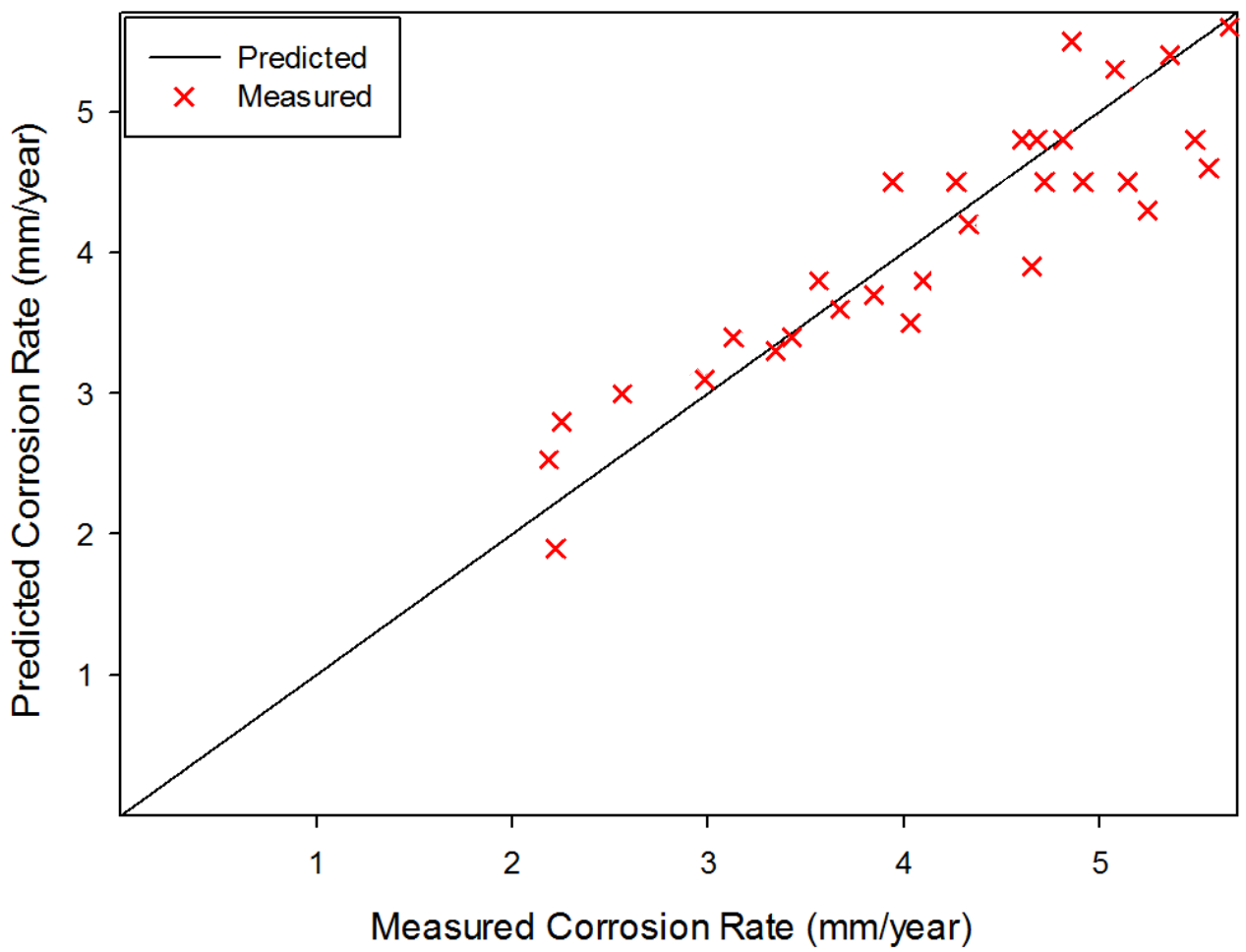

Figure 9. Comparison between measured corrosion rates and predicted corrosion rates 
Figure 10 (a) shows the predicted and experimental corrosion rates for steel with the variation of time. The simulated results are in agreement with the experimental findings. The model results show that the predicted corrosion rate is high during the initial stage. For example, when corrosion time is $1 \mathrm{~h}$, the corrosion rate reaches $26 \mathrm{~mm} /$ year, and then reduces with passing time which is in agreement with the experimental result obtained by corrosion sensor method. It can be seen that the corrosion rate decreases with the passing time. This decrease is linked with the increase in $\mathrm{pH}$ of thin water film on steel due to corrosive reactions which slows down the corrosion rate. The calculations from model show that the initial $\mathrm{pH}$ of thin water film is always less than 3 . However, with the progression of corrosive reactions with time, the $\mathrm{pH}$ of thin water film increases because of the accumulation of $\mathrm{HSO}_{3}^{-}$, which results in the gradual formation of corrosion product film. The accumulation of $\mathrm{HSO}_{3}^{-}$is directly linked with the aqueous absorption and chemical dissolution of $\mathrm{SO}_{2}$ in water droplet, as modelled in eq. 21, 22 and 23. The development of corrosion product film also inhibits the corrosion process significantly.

Fig. 10 (b) shows the corrosion rate with time variation for various values of inclination angles $\theta$ of steel. The inclination angle $\theta$ directly affects the water deposition rate on bare steel as modelled in eq. 41 . It can be seen from the modelling results that in a supersaturated environment with high $\mathrm{SO}_{2}$ concentration, as soon as the $\mathrm{SO}_{2}$ absorbed water droplet deposits on the surface of steel forming a $\mathrm{SO}_{2}-\mathrm{O}_{2}-\mathrm{H}_{2} \mathrm{O}$ thin water film, the corrosion initialises with a very high corrosion rate at the initial stage. For example, for the case when inclination angle of steel $\theta=0^{\circ}$, initially at 2 hours of corrosion time, the corrosion rate is as high as $21 \mathrm{~mm} / \mathrm{year}$. If the steel is situated at certain $\theta>0^{\circ}$ instead of flat horizontal facing $\theta=0^{\circ}$, then the effective steel area for deposition of droplets will be low which will result in low deposition rate. Therefore the thickness of water film which acts as an electrolyte for the corrosive reactions on steel will be low further accounting for low corrosion rates. At time $>20$, the inclination angle seems not to have effect on the final corrosion rates. The reason is that after this particular time the process becomes more of $\mathrm{pH}$ dependent rather than film thickness dependent. It should be noted that $\mathrm{pH}$ is not a function orientation rather it is only a function of chemical reactions. Only film thickness is a function of orientation. Therefore, at initial stage, both parameters: film thickness and $\mathrm{pH}$ equally play their part in corrosion rate therefore corrosion rate is high. However when it exceeds certain time $>20$ hours, the $\mathrm{pH}$ becomes high and dominant. At high $\mathrm{pH}$, the corrosion rate becomes lower; no matter high thick is the water film depending on its orientation.

Figure 10 (c) analyses the corrosion rate with respect to time for various values of horizontal wind speed U. It can be seen from eq. 41 that if the wind speed is as low as $U=1 \mathrm{~m} / \mathrm{s}$ (which is mostly the air speed inside the corrosion chamber), then the deposition rate of droplets on steel is high which further accounts for high corrosion rate due to the formation of thick water film. For higher wind speeds $U>1 \mathrm{~m} / \mathrm{s}$, the corrosion rate decreases. It should be noted that for the case when the wind speed is low and the droplet is in the air, then the gravity plays an important role, as it becomes the dominant factor causing more vertical fall compared to the horizontal movement of droplet in air. 


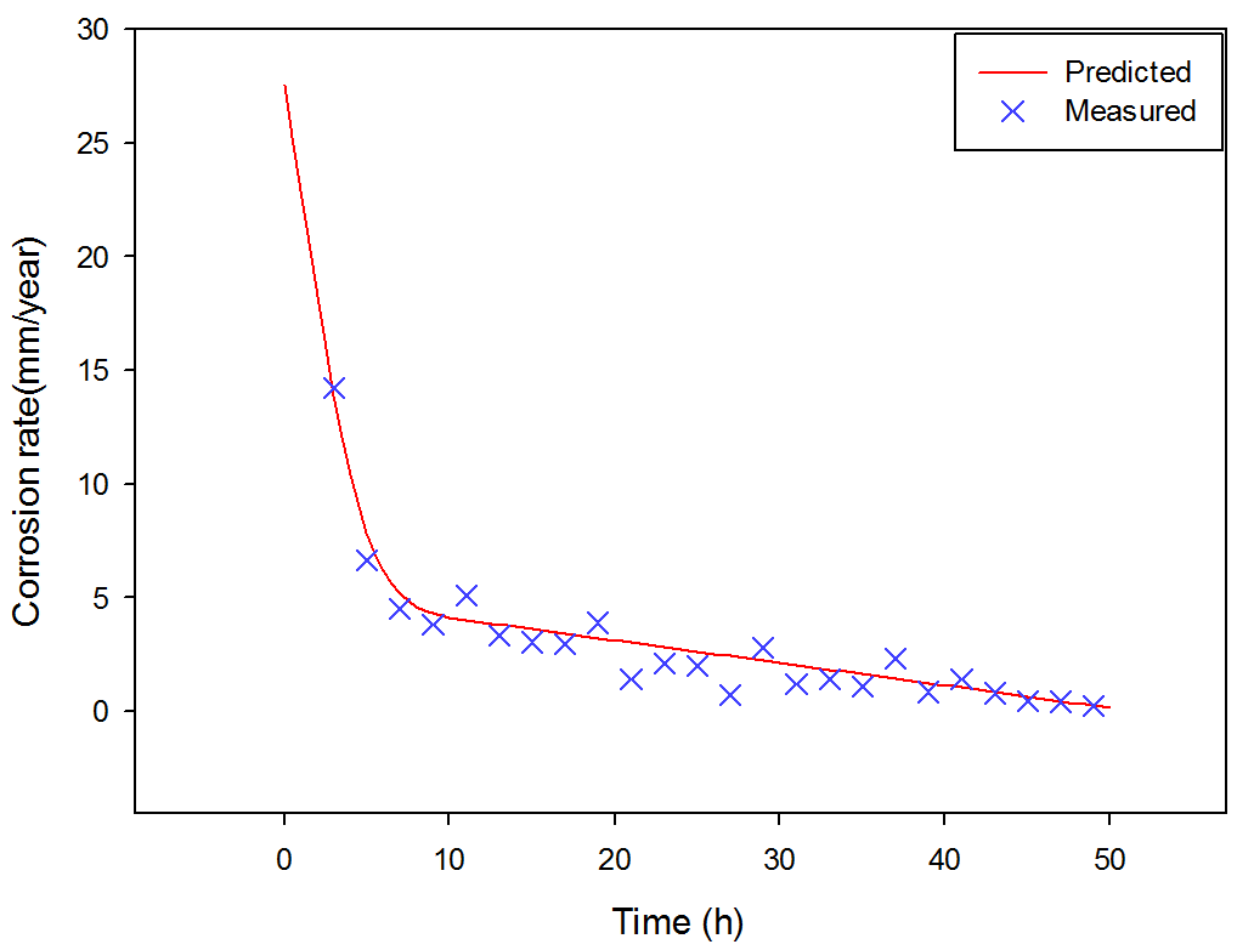

(a)

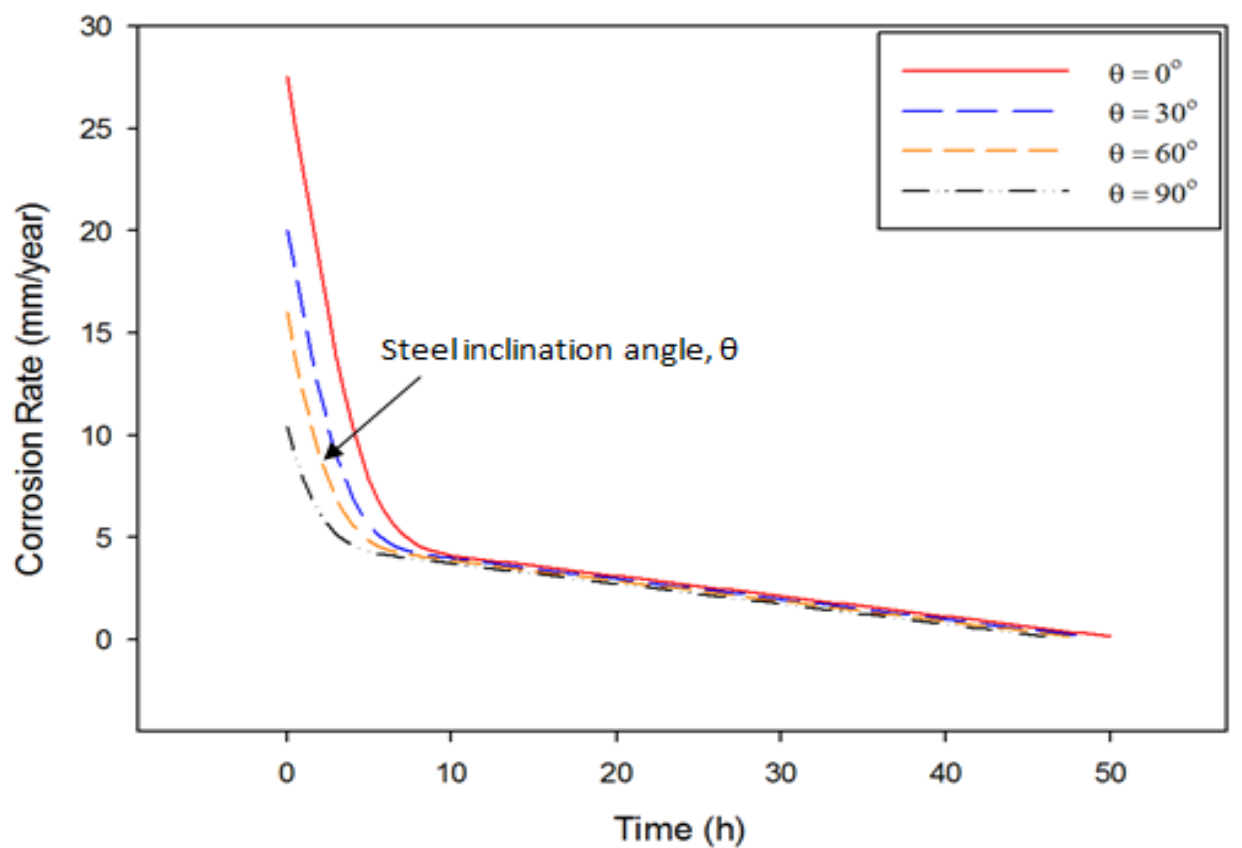

(b) 


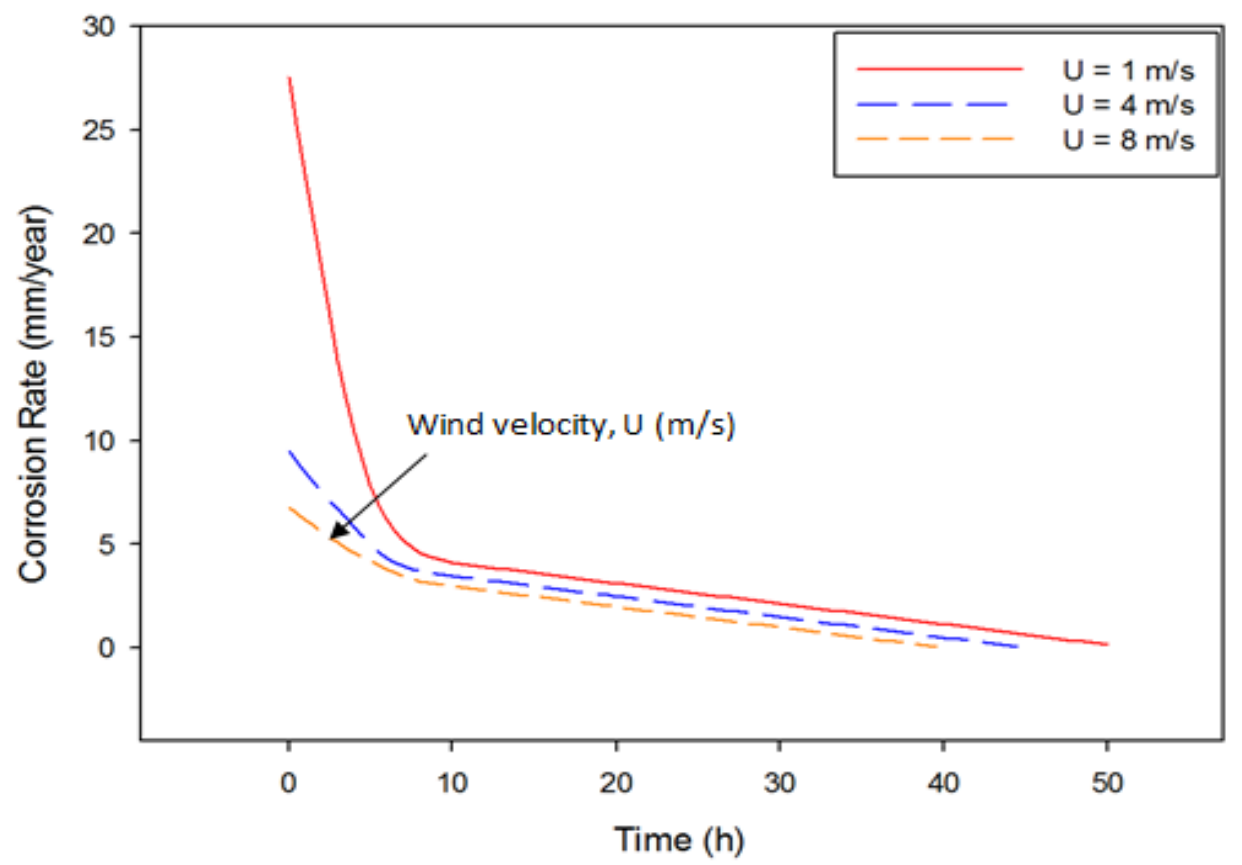

(c)

Figure 10. (a) The predicted and measured values of corrosion rate with respect to time for (b) various values of inclination angles $\theta$ of steel and (c) for various values of wind speed $U$.

Fig. 11 presents the simulated corrosion rates of steel with the variation of relative humidity for various values of time. It can be seen from the modelling results that initially the corrosion rate increases slowly until the critical relative humidity of steel is achieved at $60 \%$. The critical relative humidity is a variable term which depends on the water vapour pressure $\mathbf{p}_{\mathbf{w}}$ in eq. 5 . The critical humidity of steel is in the region of $60-62 \%$ if the atmosphere contains $\mathrm{SO}_{2}$ [53]. When the atmosphere contains impurities such as $\mathrm{SO}_{2}$, then the substrate's surface can be wetted (formation of water thin film) at lower relative humidity value therefore, reducing the critical humidity level of steel (far below $100 \%$ ). Although super-saturation occurs beyond $100 \%$, but environment contains water vapours every time, even at lower relative humidity values. These water vapours can be condensed at lower humidity values if the atmosphere contains impurities like in this case $\mathrm{SO}_{2}$. The thin film which deposits on the surface at lower relative humidity then starts absorbing large concentration of $\mathrm{SO}_{2}$ ultimately initiating the corrosion reactions at early stage. Fig. 11 illustrates that there was only a small rise in corrosion rate when the relative humidity grew from $5 \%$ to $60 \%$, meaning when relative humidity was less than the critical relative humidity $=60 \%$. It is worth noting that for the lower relative humidity values $(<60 \%)$, the anodic process may be inhibited. The passivation of anodic sites in addition to difficulty of metal ion hydration are the main causes of anodic process inhibition [53]. As the relative humidity increased beyond critical relative humidity $=60 \%$, a sharp rise in the corrosion rate was observed with the increasing relative humidity. The prediction trend shows that for such environment, the corrosion critical relative humidity of steel, beyond which the corrosion rate drastically increases lies in between 55\% and 60\% which is almost the same as was found in [53] i.e. in the rage of $60-62 \%$. The experiment [54] with low relative humidity condition revealed that the corrosion products are formed as disconnected points because of the distinct water droplets apparently deposited on the steel surface. 


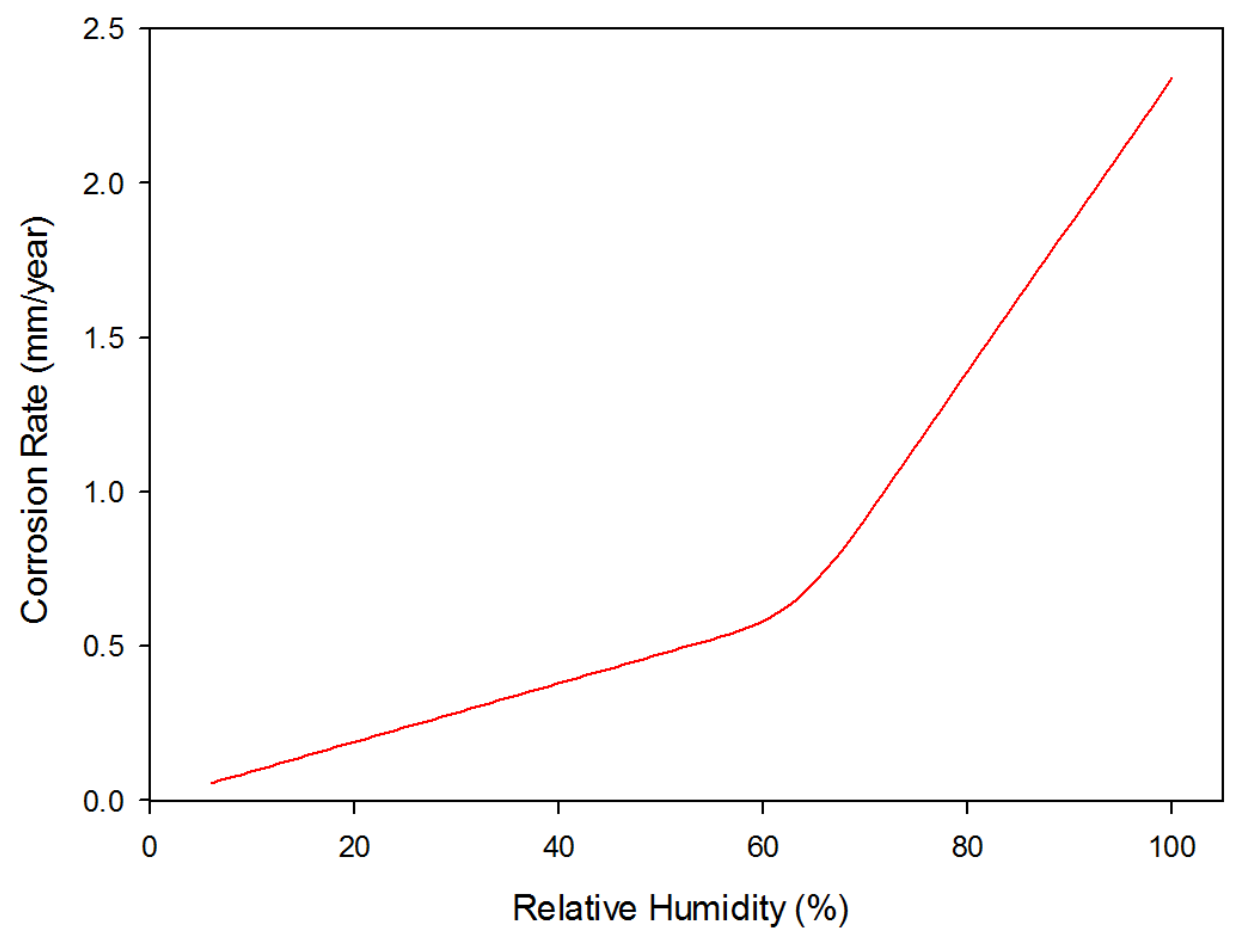

Figure 11. Predicted values of corrosion rate with the variation in relative humidity for various values of time

Fig. 12 shows the simulated values of corrosion rate with the variation of temperature. It can be seen from fig. 12 that initially, the corrosion rate increases with the increase in temperature until it reaches a peak value of 325 $\mathrm{K}$. This increase in corrosion rate is due to the increase in water vapour concentration in air and droplet growth which further accelerates the deposition and corrosion rate. When the temperature exceeds $325 \mathrm{~K}$, the evaporation rate of water droplets increases which decelerates the deposition and corrosion rate as modelled in eq. 6, 7, 8 and 9. At this stage, the corrosion product film also becomes dense which effectively decreases the corrosion rate due to barrier in $\mathrm{O}_{2}$ diffusion which acts as catalyst for corrosion process. Another reason for rising trend at the start is that with the rising temperature the diffusion rate of $\mathrm{O}_{2}$ across the thin water film increases. This results in the increasing chemical reaction forming large corrosion product on steel surface at high temperature $(325 \mathrm{~K})$. At high temperature the corrosion product has protection effect for further corrosion [54]. 


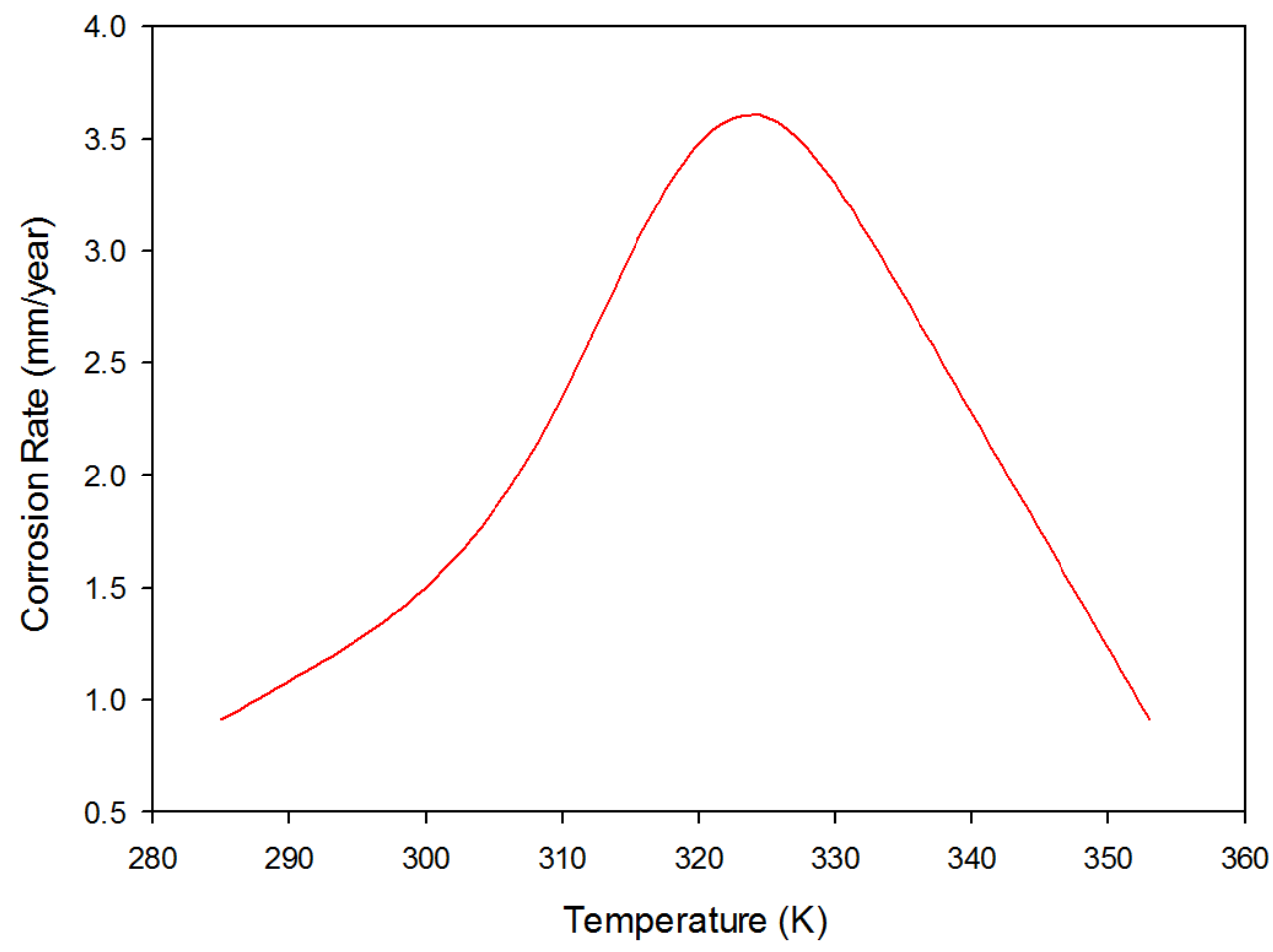

Figure 12. Predicted values of corrosion rate with the variation in temperature for various values of time

Fig. 13 shows the predicted corrosion rates for steel with the variation of $\mathrm{SO}_{2}$ concentration. The predictions show the large rise in corrosion rate right from the start when the $\mathrm{SO}_{2}$ concentration is even low, meaning that $\mathrm{SO}_{2}$ acts as a fuel for corrosion process. Fig. 13 shows the uniform corrosion rates of steel samples with different $\mathrm{SO}_{2}$ concentrations from $0.2 \%$ to $2.5 \%$. For steel samples, the increase of $\mathrm{SO}_{2}$ concentration resulted in gradual increase of uniform corrosion rate, however beyond certain concentration, the increase rate was slowed down. The reason for such trend is the gradual consumption of $\mathrm{SO}_{2}$ concentration on steel surface during corrosion process, which reduces $\mathrm{SO}_{2}$ concentration on steel surface than that away from the sample. The diffusion rates of all the dissociated ionic components of $\mathrm{SO}_{2}, \mathrm{O}_{2}$ in thin water film and corrosion product film are modelled in eq. 52. As the diffusion process continued, a film of corrosion product was formed on the surface of sample, which effectively reduced the diffusion rate and eventually corrosion rate. With the formation of corrosion product layer, the controlling process of corrosion reaction would gradually shift from the charge transfer (chemical reaction based) control to the diffusion control. For large concentrations of $\mathrm{SO}_{2}$, the diffusion rate of $\mathrm{SO}_{2}$ due to large gradient is high which delivers more $\mathrm{SO}_{2}$ to the surface of samples. However, because the concentration of $\mathrm{SO}_{2}$ in the chamber was limited therefore $\mathrm{SO}_{2}$ was gradually consumed as the reaction continued. This effect on corrosion test would be even greater when the concentration of $\mathrm{SO}_{2}$ in the chamber is low. 


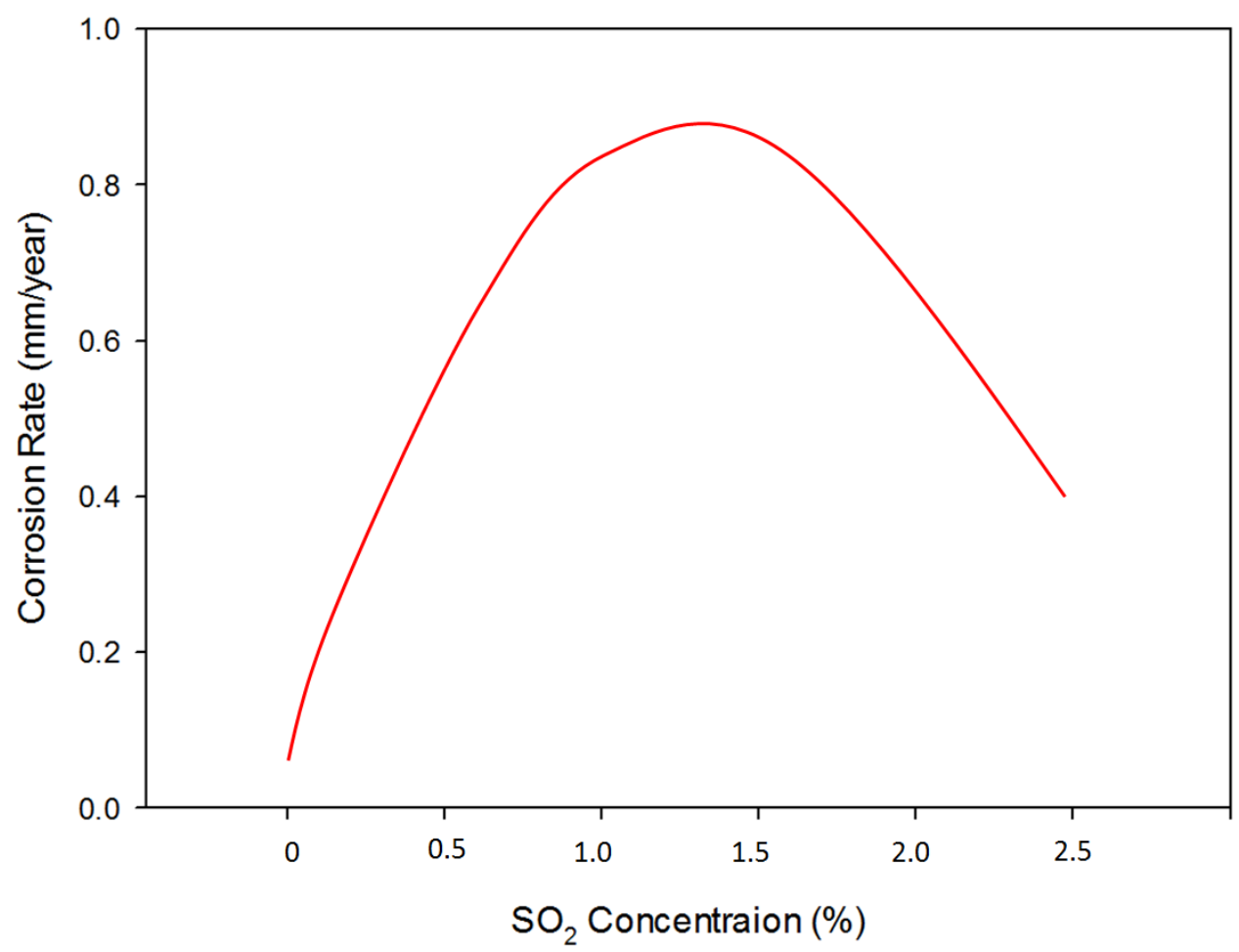

Figure 13. The predicted values of corrosion rate with the variation in $\mathrm{SO}_{2}$ concentration as a function of time

\section{Conclusions}

Continuous exposure of AISI-SAE-1010 steel samples to the moist $\mathrm{SO}_{2}$ corrosion test (ASTM - G 87) has resulted in the decreasing corrosion rate of the samples with passing time. $\mathrm{SO}_{2}$ in the presence of moisture gets converted in to bisulfite ion $\mathrm{HSO}_{3}^{-}$which upon reaction with steel produces corrosion product $\mathrm{FeSO}_{4}$. The accumulation of $\mathrm{HSO}_{3}^{-}$increases the $\mathrm{pH}$ of thin water film on steel which results in the gradual formation of corrosion product film. The development of corrosion product film also inhibits the corrosion process significantly. Based upon the experimental data a five-stage holistic model to predict the corrosion of steel under the effect of $\mathrm{SO}_{2}-\mathrm{O}_{2}-\mathrm{H}_{2} \mathrm{O}$ environments is developed. This design considers the modelling of following stages respectively: (i) the growth rate of air-suspended water droplets (i.e. moisture) depending on the condensation/evaporation rate, (ii) the transport of gas-phase $\mathrm{SO}_{2}$ to the droplets forming bisulfite ion $\mathrm{HSO}_{3}^{-}$ ions, (iii) the coalescence of these $\mathrm{SO}_{2}$ absorbed water droplets under the effects of wind speed and gravity, (iv) the deposition rate of $\mathrm{SO}_{2}$ absorbed droplets on steel substrate depending on the inclination and azimuth angles of steel surfaces and, (v) the corrosion rate of steel due to the deposition of these $\mathrm{SO}_{2}$ absorbed droplets. The incorporation of all the above stages develops a comprehensive corrosion prediction model which not only includes the electrochemical parameters but also large number of physical, environmental and material parameters.

The novelty in this model is the integration of micro-dynamic vapour pressure concepts into the corrosion modelling techniques i.e. (i) condensation/evaporation rate of air suspended water droplets, (ii) absorption rate of corrosive $\mathrm{SO}_{2}$ gas in these droplets and (iii) the deposition rate of these droplets on steel depending on wind velocity, gravity as well as the inclination and azimuthal orientations of steel. All these factors have were not considered in the corrosion modelling of steel in literature and have the values of academic and industrial applications. A comparative analysis between the model and experimental results showed that the model provided the correct decreasing trend of the corrosion rate with time. The predictive trends of corrosion rate of steel were also generated for varying values of temperature, relative humidity, and $\mathrm{SO}_{2}$ mole percent.

\section{Acknowledgements}

The authors would like to acknowledge in-kind support provided by Defence Science and Technology Laboratory (DSTL) - Ministry of Defence (Professor Keith Stokes) and The Tank Museum Bovington (Mike 
Hayton and Richard Smith). Authors would also like to thank Paola Barbuto, Stephen Fordham and Dr Dean Bernard at SciTech Bournemouth University for supporting surface analyses and measurement techniques. 


\section{References}

[1] A. Saeed, Khan, Z., and Montgomery, E., "Corrosion Damage Analysis and material Characterization of Sherman and Centaur - The Historic Military Tanks," Materials Performance and Characterization, vol. 2, pp. 30-44, February 6, 2013.

[2] A. Saeed, Z. A. Khan, M. Hadfield, and S. Davies, "Material characterization and real-time wear evaluation of pistons and cylinder liners of the tiger 131 military tank," Tribology Transactions, vol. 56, pp. 637-644, // 2013.

[3] M. H. Nazir, Z. A. Khan, A. Saeed, and K. Stokes, "A model for cathodic blister growth in coating degradation using mesomechanics approach," Materials and Corrosion, 2015.

[4] M. H. Nazir, Z. A. Khan, A. Saeed, and K. Stokes, "Modeling the Effect of Residual and DiffusionInduced Stresses on Corrosion at the Interface of Coating and Substrate," CORROSION, vol. 72, pp. 500-517, 2016/04/01 2015.

[5] A. Saeed, Z. Khan, M. Clark, N. Nel, and R. Smith, "Non-destructive material characterisation and material loss evaluation in large historic military vehicles," Insight: Non-Destructive Testing and Condition Monitoring, vol. 53, pp. 382-386, 2011.

[6] M. H. Nazir, Z. A. Khan, A. Saeed, and K. Stokes, "A predictive model for life assessment of automotive exhaust mufflers subject to internal corrosion failure due to exhaust gas condensation," Engineering Failure Analysis, vol. 63, pp. 43-60, 2016.

[7] A. Saeed, "Sustainable methodology of conserving historic military vehicles," Bournemouth University, 2013.

[8] A. Saeed, Z. A. Khan, and M. H. Nazir, "Time dependent surface corrosion analysis and modelling of automotive steel under a simplistic model of variations in environmental parameters," Materials Chemistry and Physics, vol. 178, pp. 65-73, 8/1/ 2016.

[9] M. H. Nazir, Z. A. Khan, and K. Stokes, "A holistic mathematical modelling and simulation for cathodic delamination mechanism - a novel and an efficient approach," Journal of Adhesion Science and Technology, pp. 1-39, 2015.

[10] Z. A. Khan, M. Grover, and M. H. Nazir, "The Implications of Wet and Dry Turning on the Surface Quality of EN8 Steel," in Transactions on Engineering Technologies, ed: Springer, 2015, pp. 413-423.

[11] M. H. Nazir, Z. Khan, and K. Stokes, "Modelling of metal-coating delamination incorporating variable environmental parameters," Journal of Adhesion Science and Technology, vol. 29, pp. 392-423, 2014.

[12] M. Nazir, Z. Khan, A. Saeed, and K. Stokes, "Modelling the Effect of Residual and Diffusion induced Stresses on Corrosion at the Interface of Coating and Substrate," Corrosion, 2015.

[13] M. H. Nazir, Z. A. Khan, and K. Stokes, "Optimisation of Interface Roughness and Coating Thickness to Maximise Coating-Substrate Adhesion - A Failure Prediction and Reliability Assessment Modelling," Journal of Adhesion Science and Technology, vol. 29, pp. 1415-1445, 2015.

[14] M. Nazir, Z. A. Khan, and K. Stokes, "A unified mathematical modelling and simulation for cathodic blistering mechanism incorporating diffusion and fracture mechanics concepts," Journal of Adhesion Science and Technology, vol. 29, pp. 1200-1228, 2015.

[15] M. H. Nazir, Z. A. Khan, and K. Stokes, "Analysing the coupled effects of compressive and diffusion induced stresses on the nucleation and propagation of circular coating blisters in the presence of microcracks," Engineering Failure Analysis, vol. 70, pp. 1-15, 2016.

[16] "SO2 emissions "http://www.eea.europa.eu/data-and-maps/indicators/eea-32-sulphur-dioxide-so2emissions-1"," Last accessed: 15/11/2016.

[17] D. Miller, "Corrosion control on aging aircraft: what is being done," Materials Performance, vol. 29, pp. 10-11, 1990.

[18] Z. Lu, D. G. Streets, Q. Zhang, S. Wang, G. R. Carmichael, Y. F. Cheng, C. Wei, M. Chin, T. Diehl, and Q. Tan, "Sulfur dioxide emissions in China and sulfur trends in East Asia since 2000," Atmospheric Chemistry and Physics, vol. 10, pp. 6311-6331, 2010.

[19] Z. Lu, D. G. Streets, B. de Foy, and N. A. Krotkov, "Ozone Monitoring Instrument Observations of Interannual Increases in SO2 Emissions from Indian Coal-Fired Power Plants during 2005-2012," Environmental Science \& Technology, vol. 47, pp. 13993-14000, 2013/12/17 2013.

[20] "National Air Quality: Status and Trends of Key Air Pollutants "https://www.epa.gov/air-trends"," Last accessed: 15/11/2016.

[21] "UK-Air, latest measured levels "https://uk-air.defra.gov.uk/latest/currentlevels"," Last accessed: 15/11/2016. 
[22] Y. Xiang, Z. Wang, M. Xu, Z. Li, and W. Ni, "A mechanistic model for pipeline steel corrosion in supercritical CO 2-SO 2-O 2-H 2 O environments," The Journal of Supercritical Fluids, vol. 82, pp. $1-12,2013$.

[23] H. Vasconcelos, B. Fernández-Pérez, J. Morales, R. Souto, S. González, V. Cano, and J. Santana, "Development of Mathematical Models to predict the Atmospheric Corrosion Rate of Carbon Steel in Fragmented Subtropical Environments," Int. J. Electrochem. Sci, vol. 9, pp. 6514-6528, 2014.

[24] D. R. Lide, CRC handbook of chemistry and physics: CRC press, Boca Raton, USA, 2004.

[25] D. W. Brown, R. J. Connolly, D. R. Darr, and B. Laskowski, "Linear Polarization Resistance Sensor Using the Structure as a Working Electrode," PHM Society, EUROPEAN CONFERENCE OF THE PROGNOSTICS AND HEALTH MANAGEMENT SOCIETY 2014, vol. 5, pp. 1-7, 2014.

[26] D. Brown, D. Darr, J. Morse, and B. Laskowski, "Theoretical and Experimental Evaluation of a RealTime Corrosion Monitoring System for Measuring Pitting in Aircraft Structures," First European Conference of the Prognostics and Health Management Society 2012, vol. 3, pp. 1-9, 2012.

[27] V. Feliu, J. González, C. Adrade, and S. Feliu, "Equivalent circuit for modelling the steel-concrete interface. II. Complications in applying the stern-geary equation to corrosion rate determinations," Corrosion science, vol. 40, pp. 995-1006, 1998.

[28] R. Bird, W. Stewart, E. Lightfoot, and R. E. Meredith, "Transport Phenomena," Journal of The Electrochemical Society, vol. 108, pp. 78C-79C, 1961.

[29] F. R. Newbold and N. R. Amundson, "A model for evaporation of a multicomponent droplet," AIChE journal, vol. 19, pp. 22-30, 1973.

[30] B. J. Devenish, P. Bartello, J. L. Brenguier, L. R. Collins, W. W. Grabowski, R. H. A. Ijzermans, S. P. Malinowski, M. W. Reeks, J. C. Vassilicos, L. P. Wang, and Z. Warhaft, "Droplet growth in warm turbulent clouds," Quarterly Journal of the Royal Meteorological Society, vol. 138, pp. 1401-1429, 2012.

[31] J. Kondo and S. Akashi, "Numerical studies on the two-dimensional flow in horizontally homogeneous canopy layers," Boundary-Layer Meteorology, vol. 10, pp. 255-272, 1976.

[32] G. L. Mellor and T. Yamada, "Development of a turbulence closure model for geophysical fluid problems," Reviews of Geophysics, vol. 20, pp. 851-875, 1982.

[33] A. Petroff, L. Zhang, S. C. Pryor, and Y. Belot, "An extended dry deposition model for aerosols onto broadleaf canopies," Journal of Aerosol Science, vol. 40, pp. 218-240, 2009.

[34] J. T. Davies, Turbulence phenomena: an introduction to the eddy transfer of momentum, mass, and heat, particularly at interfaces: Elsevier, 2012.

[35] S. Nesic, S. Wang, J. Cai, and Y. Xiao, "Integrated CO2 corrosion-multiphase flow model," in SPE International Symposium on Oilfield Corrosion, 2004.

[36] X. Ge, X. Wang, M. Zhang, and S. Seetharaman, "Correlation and prediction of activity and osmotic coefficients of aqueous electrolytes at $298.15 \mathrm{~K}$ by the modified TCPC model," Journal of Chemical \& Engineering Data, vol. 52, pp. 538-547, 2007.

[37] F. J. Millero, J. B. Hershey, G. Johnson, and J.-Z. Zhang, "The solubility of SO2 and the dissociation of H2SO3 in NaCl solutions," Journal of Atmospheric Chemistry, vol. 8, pp. 377-389, 1989.

[38] B. B. Benson, D. Krause Jr, and M. A. Peterson, "The solubility and isotopic fractionation of gases in dilute aqueous solution. I. Oxygen," Journal of Solution Chemistry, vol. 8, pp. 655-690, 1979.

[39] Z. Shen, S. Guo, W. Kang, K. Zeng, M. Yin, J. Tian, and J. Lu, "Kinetics and Mechanism of Sulfite Oxidation in the Magnesium-Based Wet Flue Gas Desulfurization Process," Industrial \& Engineering Chemistry Research, vol. 51, pp. 4192-4198, 2012/03/21 2012.

[40] A. Tatani, T. Imai, and Y. Fujima, "Effect of Mn2+ on sulfite oxidation in limestone scrubbing," Energy \& fuels, vol. 18, pp. 54-62, 2004.

[41] Y. Xiang, Z. Wang, Z. Li, and W. Ni, "The impact of corrosion product scales on the corrosion rates of $\mathrm{X} 70$ steel in supercritical CO2 with $\mathrm{SO} 2$ and $\mathrm{H} 2 \mathrm{O}$ impurities," in The World Congress on Engineering and Technology (CET), IEEE, Shanghai, 2011, pp. 498-504.

[42] J. W. Mullin, Crystallisation: Butterworths London, 1972.

[43] N. Li, J. J. Hefferren, and K. a. Li, Quantitative chemical analysis: World Scientific, 2013.

[44] S. Nesic, J. Postlethwaite, and S. Olsen, "An electrochemical model for prediction of corrosion of mild steel in aqueous carbon dioxide solutions," Corrosion, vol. 52, pp. 280-294, 1996.

[45] S. Nesic, N. Thevenot, J. L. Crolet, and D. Drazic, "Electrochemical properties of iron dissolution in the presence of CO2-basics revisited," in CORROSION 96, 1996.

[46] R. Winston Revie, "Uhlig's Corrosion Handbook 2nd edition," Anti-Corrosion Methods and Materials, vol. 47, 2000.

[47] W. M. Haynes, CRC handbook of chemistry and physics: CRC press, 2014.

[48] W. Shen, Z. M. Jiang, and J.-G. Tong, "Engineering thermodynamics," Higher Education Press, Beijing, 2001. 
[49] Z. Levin and B. Machnes, "Experimental evaluation of the coalescence efficiencies of colliding water drops," pure and applied geophysics, vol. 115, pp. 845-867, 1977.

[50] J. Anthony, R. Bideaux, K. Bladh, and M. Nichols, "Handbook of Mineralogy, 1, 588p. Mineralogical Society of America, Chantilly," ed, 2003.

[51] D. G. Leaist, "Diffusion coefficient of aqueous sulfur dioxide at 25. degree. C," Journal of Chemical and Engineering Data, vol. 29, pp. 281-282, 1984.

[52] P. Lorbeer and W. Lorenz, "The kinetics of iron dissolution and passivation in solutions containing oxygen," Electrochimica Acta, vol. 25, pp. 375-381, 1980.

[53] X. Li, C. Dong, K. Xiao, C. Du, H. Zhou, and C. Lin, "The Initial Corrosion Behavior and Mechanism of Metal in Atmosphere," ed: Science Press, Beijing, 2009.

[54] S. Nešić, "Key issues related to modelling of internal corrosion of oil and gas pipelines-A review," Corrosion Science, vol. 49, pp. 4308-4338, 2007. 